Article

\title{
Optimization of Corrosion Wear Resistance of the NiCrBSi Laser-Clad Coatings Fabricated on Ti6A14V
}

\author{
Wanggen Li, Jun $\mathrm{Li}^{*}$ and Yinsi Xu
}

Citation: Li, W.; Li, J.; Xu, Y. Optimization of Corrosion Wear Resistance of the NiCrBSi Laser-Clad Coatings Fabricated on Ti6Al4V. Coatings 2021, 11, 960. https:// doi.org/10.3390/coatings11080960

Academic Editor: Yingtao Tian

Received: 20 July 2021

Accepted: 10 August 2021

Published: 13 August 2021

Publisher's Note: MDPI stays neutral with regard to jurisdictional claims in published maps and institutional affiliations.

Copyright: (c) 2021 by the authors. Licensee MDPI, Basel, Switzerland. This article is an open access article distributed under the terms and conditions of the Creative Commons Attribution (CC BY) license (https:// creativecommons.org/licenses/by/ $4.0 /)$.
School of Materials Engineering, Shanghai University of Engineering Science, Shanghai 201620, China; lwg2020Y@163.com (W.L.); 18238237071@163.com (Y.X.)

* Correspondence: jacob_lijun@sues.edu.cn; Tel.: +86-21-67791198; Fax: +86-21-67791377

\begin{abstract}
Ni-based alloy powder (NiCrBSi) was applied to prepare coatings on Ti6Al4V by laser cladding to improve the wear resistance of the latter under corrosion. The scanning speed was found to be an essential parameter that could adjust the microstructure of the coatings. Changes in the microstructures of the coatings with the scanning speed were highlighted, and the relationships between the microstructures and microhardness, fracture toughness, corrosion, and corrosion wear resistance of the coatings were established. Results indicated that the matrix changes from $\mathrm{Ti}_{2} \mathrm{Ni}$ + TiNi to primary $\gamma(\mathrm{Ni})+$ eutectics $\left(\gamma(\mathrm{Ni})+\mathrm{Ni}_{3} \mathrm{Ti}\right)$ with increasing scanning speed. Moreover, reinforcement phases changed from $\mathrm{TiB}_{2}+\mathrm{TiC}\left(5 \mathrm{~mm} \cdot \mathrm{s}^{-1}\right)$ to $\mathrm{TiB}_{2}+\mathrm{TiC}+\mathrm{Cr}_{7} \mathrm{C}_{3}\left(11 \mathrm{~mm} \cdot \mathrm{s}^{-1}\right)$ to $\mathrm{TiB}_{2}+\mathrm{TiC}+\mathrm{Cr}_{7} \mathrm{C}_{3}+\mathrm{CrB}\left(17 \mathrm{~mm} \cdot \mathrm{s}^{-1}\right)$. The average microhardness of the coatings first increased and then decreased, and the corresponding fracture toughness showed the opposite trend. The optimum combination of these properties was observed in the coating prepared at $11 \mathrm{~mm} \cdot \mathrm{s}^{-1}$. This coating demonstrated excellent wear resistance in $3.5 \mathrm{wt} . \% \mathrm{NaCl}$ solution, as well as a high corrosion potential, a low corrosion current density, and a low current density when the electrode initially entered a comparatively stable corrosion state. Moreover, compared with coatings prepared at other scanning speeds, this coating revealed a higher critical potential for oxidation film destruction. The results of this research collectively show that regulating the microstructures of laser-clad coatings by applying different scanning speeds is a feasible strategy to optimize the wear resistance of the coatings under corrosion.
\end{abstract}

Keywords: laser-clad; NiCrBSi; microstructural change; wear resistance

\section{Introduction}

Ti alloys with high specific strength and excellent corrosion resistance have been widely utilized in the biocompatibility [1], aerospace [2], chemical [3], medical [4], and other fields. However, these materials are unsuitable for use in friction components, which must come into contact with other components and undergo relative motion. The alloys are generally known to show low hardness, which endows them with very poor resistance to microcutting and accelerates their failure $[5,6]$. Thus, surface modification, usually by preparing hard coatings over the alloys, is recommended to improve their wear resistance and expand their applications as friction components. Laser cladding, as a promising surface-modification method [7,8], has sparked great research attention on account of its outstanding features, which include tailorable microstructures and thickness and strong metallurgical binding with the substrate.

The selection of the cladding material is a crucial consideration that is directly responsible for the resultant properties of the coating. The most frequently applied materials mainly consist of Ni-based [9,10], Co-based [11,12], Fe-based [13,14], Ti-based [15,16], and equimolar [17] alloys. Nazari et al. [18] prepared a novel Ti-based coating on Ti6Al4V by laser cladding using low-cost recycled nano-crystalline Ti powder as the cladding material. The in situ synthesized $\mathrm{Fe}_{2} \mathrm{O}_{3}$ and $\mathrm{Fe}_{2} \mathrm{C}$, along with $\mathrm{TiC}$ and $\mathrm{TiO}_{2}$ phases, significantly improved the hardness (620-815 HV) and wear resistance of the resultant coatings. Rahman 
Rashid et al. [19] fabricated two Ti-based coatings with a wrought Ti grade 5 plate as the substrate by laser cladding Ti6Al4V and Ti6Al4V0.04B powder. The introduction of trace B resulted in improvements in the hardness of the coatings from 390-450 HV to 510-600 HV, which is mainly attributed to the synthesis of very hard TiB precipitates. Xiang et al. [17] successfully synthesized a ternary CoNiTi medium-entropy alloy coating on pure Ti substrates by laser cladding. $\mathrm{BCC}$ dendrites and $\mathrm{Ti}_{2} \mathrm{Ni}$ interdendrites were observed in the coating, and a large number of $\mathrm{Ti}_{2} \mathrm{Co}$ nanoparticles precipitated inside the dendrites. The coating demonstrated a hardness of $571 \pm 46 \mathrm{HV}$, which is much higher than that of the substrate (114 $\pm 4 \mathrm{HV})$.

Commercial Ni-based alloys are particularly favorable in laser cladding because of their outstanding advantages of high hardness, good wear resistance, and excellent corrosion resistance [20-23]. Ni-based alloys are usually composed of non-metallic elements (e.g., B, C) and metallic elements (e.g., Ni, Cr, Si). Given the good affinity between these two types of elements, some borides and carbides with high hardness can be in situ synthesized as reinforcements during cladding, thus greatly improving the resistance of the resulting Ni-based coatings to microcutting [23-25]. Wang et al. [26] employed Ni60 alloy powder with $5 \mathrm{wt} . \% \mathrm{Ti}_{3} \mathrm{SiC}_{2}$ to modify the surface of $\mathrm{Ti} 6 \mathrm{Al} 4 \mathrm{~V}$ by laser cladding. The coating obtained mainly contained $\gamma(\mathrm{Ni}), \mathrm{Ti}_{x} \mathrm{Ni}_{y}$, and $\mathrm{TiC} / \mathrm{TiB}$, which offer strong resistance to microcutting; specifically, the hardness of the coating was approximately 3.2-fold that of the substrate. Friction and wear tests were carried out in air at room temperature, 300 and $600{ }^{\circ} \mathrm{C}$, and the coating demonstrated lower wear rates than the substrate at all temperatures tested (i.e., $35.96 \times 10^{-5}, 25.99 \times 10^{-5}$, and $15.18 \times 10^{-5} \mathrm{~mm}^{3} \cdot \mathrm{N}^{-1} \cdot \mathrm{m}^{-1}$ for the substrate versus $3.07 \times 10^{-5}, 1.47 \times 10^{-5}$, and $0.77 \times 10^{-5} \mathrm{~mm}^{3} \cdot \mathrm{N}^{-1} \cdot \mathrm{m}^{-1}$ for the coating); in addition, the wear rate of the coating was greatly reduced by approximately $91.46 \%, 94.35 \%$, and $94.93 \%$ relative to those of the substrate. Wu et al. [27] prepared laser-clad coatings on Ti6Al4V with $80 \mathrm{wt} . \%$ Ni60 alloy, $2 \mathrm{wt} . \%$ C, $10 \mathrm{wt} . \%$ TiN, and $8 \mathrm{wt} . \%$ Mo mixed powders as the cladding material. The $\gamma(\mathrm{Ni}), \mathrm{Ni}_{4} \mathrm{~B}_{3}, \mathrm{Ti}(\mathrm{C}, \mathrm{N}), \mathrm{TiC}, \mathrm{TiN}, \mathrm{Cr}_{2} \mathrm{~B}$, and $\mathrm{Cr}_{7} \mathrm{C}_{3}$ phases were in situ synthesized in the coatings, and the microhardness of the coating reached $1180 \mathrm{HV}_{0.2}$, which is over 3.5 times that of the substrate $\left(336.8 \mathrm{HV}_{0.2}\right)$. The wear volume $\left(4.50 \times 10^{-3} \mathrm{~mm}^{3} \cdot \mathrm{min}^{-1}\right)$ of the coating was also reduced by 26.7 times compared with that of the substrate $\left(120.28 \times 10^{-3} \mathrm{~mm}^{3} \cdot \mathrm{min}^{-1}\right)$. Gao et al. [28] produced a coating on Ti6Al4V by cladding a $50 \mathrm{wt} . \% \mathrm{NiCrBSi}-20 \mathrm{wt} . \% \mathrm{TiN}-30 \mathrm{wt} . \% \mathrm{WS}_{2}$ mixture. The coating mainly included continuous matrix phases of $\gamma(\mathrm{Ni}) / \mathrm{Ti}_{x} \mathrm{Ni}_{y}$, reinforcement phases of TiNi and TiW, and a lubricant phase of TiS. The average microhardness of this coating effectively improved to $842 \mathrm{HV}_{0.2}$ compared with that of the substrate $\left(370.0 \mathrm{HV}_{0.2}\right)$. Moreover, the coating demonstrated excellent wear resistance because of its lower wear rate $\left(10 \mathrm{~mm}^{3} \cdot \mathrm{N}^{-1} \cdot \mathrm{m}^{-1}\right)$ compared with that of the substrate $\left(22 \mathrm{~mm}^{3} \cdot \mathrm{N}^{-1} \cdot \mathrm{m}^{-1}\right)$. Similar research findings have been reported in the literature [29-31], and all of these works confirm the good applicability of Ni-based alloys for laser cladding materials. Other $\mathrm{Ni}$ based coatings, such as NiCoCrAlYSi coatings on GH4169 [32] and NiAlVNbB coatings on SUS304 [33], have also been produced.

However, despite their many benefits, previous investigations are limited by their focus on the selectivity of Ni-based alloys and other directly added ceramic phases, as well as the effect of the content of a given ceramic on the microstructural and mechanical properties of the resulting coatings [34,35]. As mentioned earlier, non-metallic and metallic elements in commercial Ni-based alloys may interact with each other to in situ synthesize high-hardness reinforcements. Although the introduction of ceramics may further improve the hardness of the coating, the cracking susceptibility of the latter may also be enhanced [36,37]. Moreover, the interface between the introduced ceramics and matrix may be contaminated and show poor compatibility, thus further aggravating the cracking susceptibility of the coating. Wear performance, as a comprehensive mechanical property, is well known to be closely associated with the resistance to microcutting and brittle debonding. The former depends on the hardness of the material, and the latter is related to the material's cracking susceptibility. Improvements in hardness may improve 
the resistance to microcutting and reduce the resistance to brittle debonding resulting from high cracking susceptibility. These combined effects may cause a reduction in wear resistance, especially when the material has been in service for a long period of time [38-40]. Moreover, previous investigations on the wear resistance of Ni-based laser-clad coatings were performed in air [41,42], which cannot represent the service performance under more extreme circumstances, such as corrosion conditions. Therefore, research on the changes in the microstructural and mechanical properties of pure Ni-based alloy powder without directly adding ceramics by modifying the process parameters (e.g., scanning speed) is necessary. Then, an optimum combination of hardness and fracture toughness is sought, in which the outstanding wear resistance is endowed.

The present investigation aimed to fabricate coatings on Ti6Al4V via direct laser cladding of pure commercial Ni-based alloy powder (NiCrBSi) without adding any ceramic phase. Ceramic phases were synthesized in situ by the reactions occurring between non-metallic and metallic elements in NiCrBSi and Ti6Al4V to avoid the shortcomings encountered in previous investigations. The microstructure of the coatings was also flexibly regulated by modulating the scanning speed. The relationships between the microstructures and properties (e.g., hardness, fracture toughness, corrosion, and wear performance in $\mathrm{NaCl}$ solution) of the coatings obtained at different scanning speeds were established. Finally, the scanning speed resulting in a coating demonstrated optimal corrosion wear resistance was confirmed.

\section{Materials and Methods}

\subsection{Preparation of the Coatings}

A Ti6Al4V alloy rod measuring $50 \mathrm{~mm}$ diameter and $50 \mathrm{~cm}$ in length was used to prepare the substrate. The rod was subjected to annealing and contained a large amount of $\alpha$ phases and traces of $\beta$ phases. The hardness of the rod was measured to be approximately $360 \mathrm{HV}$. The rod was cut into several plates measuring $50 \mathrm{~mm}$ in diameter and $10 \mathrm{~mm}$ in thickness by using a wire-cut EDM machine, and these plates were employed as substrates. The substrates were polished using 180\# SiC sandpaper and then cleaned in acetone for $20 \mathrm{~min}$ by using an ultrasonic cleaner. The selected cladding powder (Shanghai Smick Welding Materials Co., Ltd., Shanghai, China) was a pure Ni-based alloy (F102 type: $\mathrm{NiCrBSi}$ ) with particle sizes of 50-100 $\mu \mathrm{m}$ and chemical composition (wt.\%) of $16 \mathrm{Cr}$, $4 \mathrm{~B}, 4 \mathrm{Si}$, and balance $\mathrm{Ni}$. The surfaces of the substrates were coated with a thin layer of adhesive (4\% polyvinyl alcohol), after which the plates were placed in a circular mold measuring $50.3 \mathrm{~mm}$ in inner diameter and $11.0 \mathrm{~mm}$ in height. The powder was filled into the voids on the substrates with approximately $50 \mathrm{~mm}$ in diameter and $1.0 \mathrm{~mm}$ in height and then compressed for $120 \mathrm{~s}$ under a load of $30 \mathrm{MPa}$ on a BJ-30 tablet press. The complete preparation process is shown in Figure 1. Finally, a YSL-5000 fiber laser system (IPG Photonics Corporation, Oxford, MS, USA) was utilized to obtain the coatings under a power of $3 \mathrm{~kW}$, spot diameter of $6 \mathrm{~mm}$, and different scanning speeds (Coating 1: $5 \mathrm{~mm} \cdot \mathrm{s}^{-1}$; Coating 2: $11 \mathrm{~mm} \cdot \mathrm{s}^{-1}$; Coating 3: $17 \mathrm{~mm} \cdot \mathrm{s}^{-1}$ ).

\subsection{Microstructural Characterization}

The phase components of the coatings were examined using a Panalytical $X^{\prime}$ Pert Pro X-ray diffractometer (XRD) (Malvern Panalytical Co., Ltd., Shanghai, China) with $\mathrm{Cu} \mathrm{K} \alpha$ radiation $(\lambda=0.1540560 \mathrm{~nm})$. Morphological observation and chemical analyses were carried out on a Hitachi S-3400 scanning electron microscope (SEM) (Hitachi, Tokyo, Japan) equipped with a GENESIS EDAX energy-dispersive spectrometer (EDS) (EDAX Inc., Philadelphia, PA, USA). The high-vacuum model (no less than $0.1 \mathrm{MPa}$ ) was applied, and two types of detectors, namely, a secondary electron detector $(\leq 3.0 \mathrm{~nm}$ at $30 \mathrm{kV})$ and a backscattered electron detector $(\leq 4.0 \mathrm{~nm}$ at $30 \mathrm{kV})$, were utilized. The specimens were observed under magnifications of $500 \times$ and $2000 \times$. Samples for metallographic observation were polished with 180-2000\# sandpaper and $1.0 \mu \mathrm{m}$ diamond paste and 
then etched for $35 \mathrm{~s}$ with a mixture containing $4 \mathrm{ml}$ of deionized $\mathrm{H}_{2} \mathrm{O}, 6 \mathrm{~mL}$ of $\mathrm{HNO}_{3}$, and $0.4 \mathrm{~mL}$ of HF.

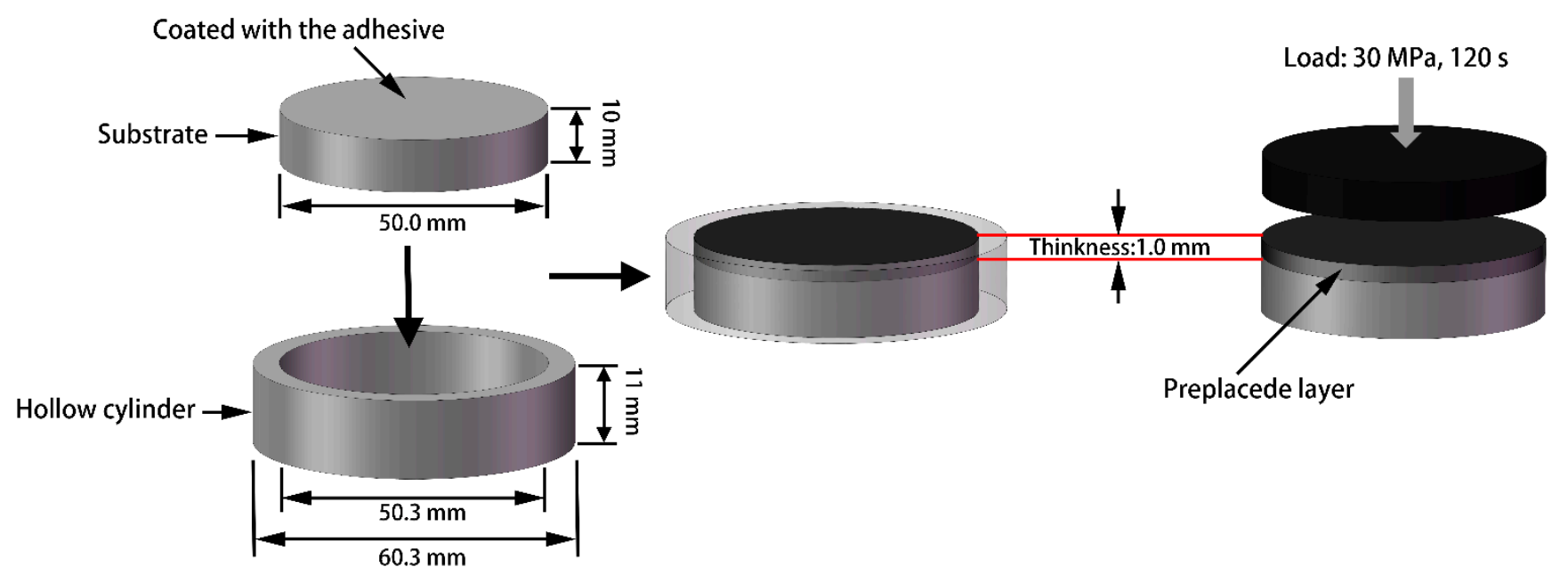

Figure 1. The schematic drawing of the complete preparation process of the preplaced layer.

\subsection{Mechanical Properties Tests}

\subsubsection{Microhardness Tests}

The microhardness of polished surfaces of metallographic samples was determined with an XHD-1000TMSC/LCD Vickers hardness tester (Shanghai Taiming Optical Instrument Co., Ltd., Shanghai, China) under a load of $200 \mathrm{gf}$ and a time of $15 \mathrm{~s}$. The microhardness was obtained in several areas throughout the cross-section of the samples at $0.1 \mathrm{~mm}$ intervals. Three measurements were collected from each area, and the average of these measurements was regarded as the final result to reduce errors. A small load of $10 \mathrm{gf}$ was also used to determine the microhardness of the given reinforcement.

\subsubsection{Fracture Toughness Tests}

The fracture toughness of the coatings was measured via the Vickers indentation method to evaluate their cracking susceptibility. First, Vickers indentations were prepared on the cross-sections of the coatings under an applied load of $3 \mathrm{kgf}$ for $15 \mathrm{~s}$ by a HV-120 Vickers microhardness testing machine (Shanghai Material testing Machine Factory, Shanghai, China). Then, the indentations and cracks around these indentations were observed by an XTL-18A optical microscope (OM) (Shanghai Dilun Optical Instrument Co., Ltd., Shanghai, China) under a magnification of $200 \times$ to obtain the lengths of the indentation diagonal lines and cracks (Figure 2). The fracture toughness was calculated according to the following formula [43]:

$$
K_{\mathrm{IC}}=0.079\left(\frac{P}{a^{3 / 2}}\right) \log \left(4.5 \frac{a}{c}\right), \text { for } 0.6 \leq \frac{c}{a} \leq 4.5
$$

where $K_{\mathrm{IC}}$ denotes the fracture toughness $\left(\mathrm{MPa} \cdot \mathrm{m}^{1 / 2}\right)$ of the samples, $P$ represents the applied load $(\mathrm{N}), a$ is the half length of the indentation diagonal line $(\mathrm{m})$, and $c$ signifies the half length of the crack (m). 


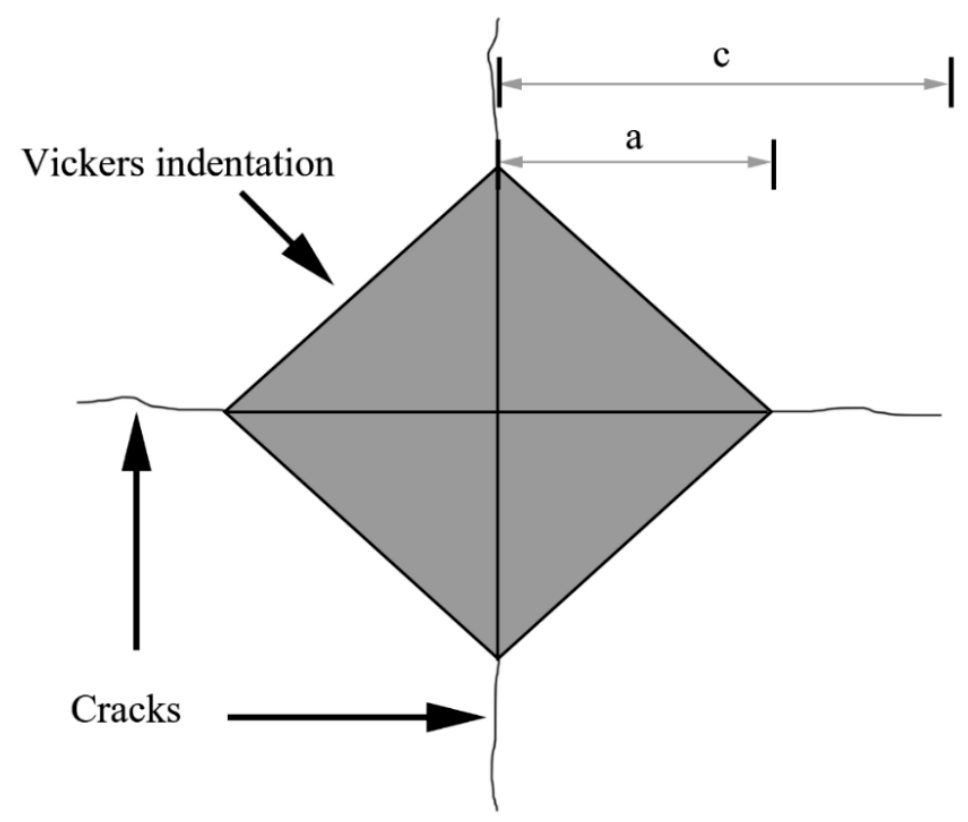

Figure 2. Schematic diagram of the indentation.

\subsubsection{Wear Tests}

The wear resistance of the coatings was evaluated by a CFT-I functional friction tester in reciprocating mode with a load of $10 \mathrm{~N}$, sliding time of $300 \mathrm{~min}$, rotating speed of $600 \mathrm{rpm}$, and reciprocating distance of $3 \mathrm{~mm}$. High-hardness $\mathrm{Si}_{3} \mathrm{~N}_{4}$ ceramic balls with a diameter of $5 \mathrm{~mm}$ were chosen as the counterpart. The tests were performed in $3.5 \mathrm{wt} . \%$ $\mathrm{NaCl}$ solution. After the tests, a surface profiler (MT-500) as a kind of two-dimensional probe contact profiler with a high resolution of $0.02 \mu \mathrm{m}$ was used to measure the wear profiles. The probe of the profiler was initially placed on a surface that was not subject to wearing, moved along the direction perpendicular to the wear tracks, and then passed through the wear tracks. The wear profiles were clearly presented on a computer monitor, and the wear volumes of the samples were automatically calculated. The whole track was divided into three equal parts, and the wear profiles of each zone was measured to reduce errors. That is to say, three wear profiles (i.e., three wear volumes) were obtained for a specific wear track. The average value was calculated as the final value of the wear track. Wear morphologies were analyzed using SEM coupled with EDS under conditions similar to those employed for microstructural observations, except that only the backscattered electron detector $(\leq 4.0 \mathrm{~nm}$ at $30 \mathrm{kV})$ was utilized. Observations were conducted under magnifications of $200 \times$ and $500 \times$. The wear rate $(K)$ of the coatings and substrate was calculated using the following formula [44]:

$$
\mathrm{K}=\frac{V}{N \times d}
$$

where $V$ is the wear volume $\left(\mathrm{mm}^{3}\right), N$ is the applied load $(\mathrm{N})$, and $d$ is the sliding distance $(\mathrm{m})$.

\subsection{Electrochemical Performance Tests}

The electrochemical performance of the samples was tested in the $3.5 \mathrm{wt} . \% \mathrm{NaCl}$ solution at room temperature on a CHI 760E electrochemical workstation (Shanghai Chenhua Instrument Co., Ltd., Shanghai, China). The traditional three-electrode system was adopted, including the samples as the working electrode (diameter, $0.25 \mathrm{~cm}$ ), a Pt plate as the auxiliary electrode, and a saturated calomel electrode as the reference electrode. Prior to the tests, the samples were immersed in the solution for $30 \mathrm{~min}$, and the open circuit potential was measured for $400 \mathrm{~s}$ to obtain a stable value. Potentiodynamic polarization 
curves were plotted under a potential window of -0.8 to $1.0 \mathrm{~V}$ with a scanning speed of $1 \mathrm{mV} \cdot \mathrm{s}^{-1}$. The resultant surfaces of the samples were detected to analyze chemical valences and the contents of metallic elements in the oxidation films by using an ESCALAB 250XI X-ray photoelectron spectroscope (XPS) (Thermo Fisher Scientific, Waltham, MA, USA).

\section{Results and Discussion}

\subsection{Microstructural Characterization}

Figure 3 presents the XRD diffraction patterns of the coatings fabricated at different scanning speeds. The main peaks of Coating 1 could clearly be observed at $2 \theta=36.123^{\circ}$, $2 \theta=39.087^{\circ}, 2 \theta=41.560^{\circ}, 2 \theta=42.460^{\circ}, 2 \theta=44.482^{\circ}, 2 \theta=61.141^{\circ}$, and $2 \theta=77.745^{\circ}$. Comparison of the $d$ values of these peaks with those in the corresponding JCPDS cards confirmed that $\mathrm{TiNi}$ and $\mathrm{Ti}_{2} \mathrm{Ni}$ were formed as the matrix phase, while $\mathrm{TiC}$ and $\mathrm{TiB}_{2}$ were formed as the reinforcement phase during laser cladding. The four compounds are rich in $\mathrm{Ti}$, which indicates that this element plays a dominant role in the resultant phases of the coating. The coating obtained at a scanning speed of $11 \mathrm{~mm} \cdot \mathrm{s}^{-1}$ revealed an XRD diffraction pattern showing significant changes compared with that obtained for Coating 1; this finding implies that the phase constituents of these coatings have obvious differences. The indexed result shows that the matrix phases of Coating 2 are $\gamma(\mathrm{Ni})$ and $\mathrm{Ni}_{3} \mathrm{Ti}_{\text {, which }}$ are significantly different from those formed in Coating $1 . \mathrm{TiB}_{2}$ and $\mathrm{TiC}$ were still observed, along with four new peaks related to $\mathrm{Cr}_{7} \mathrm{C}_{3}$ at $2 \theta=41.886^{\circ}, 2 \theta=44.242^{\circ}, 2 \theta=49.872^{\circ}$, and $2 \theta=81.099^{\circ}$. Ni and $\mathrm{Cr}$ as the main elements in Coating 2 greatly influenced the phase constituents of the coating ad weakened the role of Ti. When the scanning speed was increased to $17 \mathrm{~mm} \cdot \mathrm{s}^{-1}$, the XRD diffraction pattern obtained demonstrated slight changes relative to that of Coating 2. Specifically, an increase in the intensity of the main peaks associated with $\gamma(\mathrm{Ni})$ and $\mathrm{Cr}_{7} \mathrm{C}_{3}$ and the appearance of some new peaks associated with $\mathrm{CrB}$ were found. This result implies that the cladding material plays a significant role in the phase constituents of the coating at high scanning speeds. The changes observed in the XRD patterns may be mainly attributed to increases in scanning speed, which causes great reductions in the dilution ratio (D) of the coatings. The $\mathrm{D}$ of all coatings could be calculated by the following formula:

$$
\mathrm{D}=\frac{d_{p}}{d_{p}+t_{c}}
$$

where $d_{p}$ refers to the penetration depth of the melt pool below the substrate and $t_{c}$ represents the thickness of the melt pool above the original substrate level.

The calculated D values show a downward trend with increasing scanning speed (Coating 1, 64.7\%; Coating 2, 53.9\%; Coating 3, 37.3\%). Rahman Rashid et al. [45] investigated the effects of specific energy (specific energy $=$ laser power $/$ (scanning speed $\times$ beam diameter)) on $\mathrm{D}$. The results indicated that the $\mathrm{D}$ of the laser-clad coatings is closely related to the specific energy; specifically, the average D of the coatings gradually increased with decreasing specific energy. This finding is contrary to the results obtained in the present research. This difference in results may be attributed to differences in the powder feeding method between the two studies. In the present study, powder layers with a constant thickness were placed on Ti6Al4V prior to laser cladding, which means the amount of molten powder was constant in all zones during laser cladding. That is to say, the specific energy could be regarded as the only essential factor responsible for D. However, the study reported in [46] delivered the powder by a coaxial nozzle during laser cladding, which means the amount of molten powder may vary at different specific energies. In addition to the specific energy, the molten powder is another factor strongly affecting $D$. Under the given feeding rate, beam diameter, and laser power, increases in scanning speed cause a reduction in specific energy and, in turn, a reduction in $\mathrm{D}$ because of the reduction in $d_{p}$. However, the amount of molten powder correspondingly decreased, thereby causing an increase in $\mathrm{D}$ owing to the reduction in $t_{c}$. When the role of the latter suppresses that of the 
former, D may present an upward tendency with increasing scanning speed, as reported in Ref. [46], which contradicts the findings in the present study.

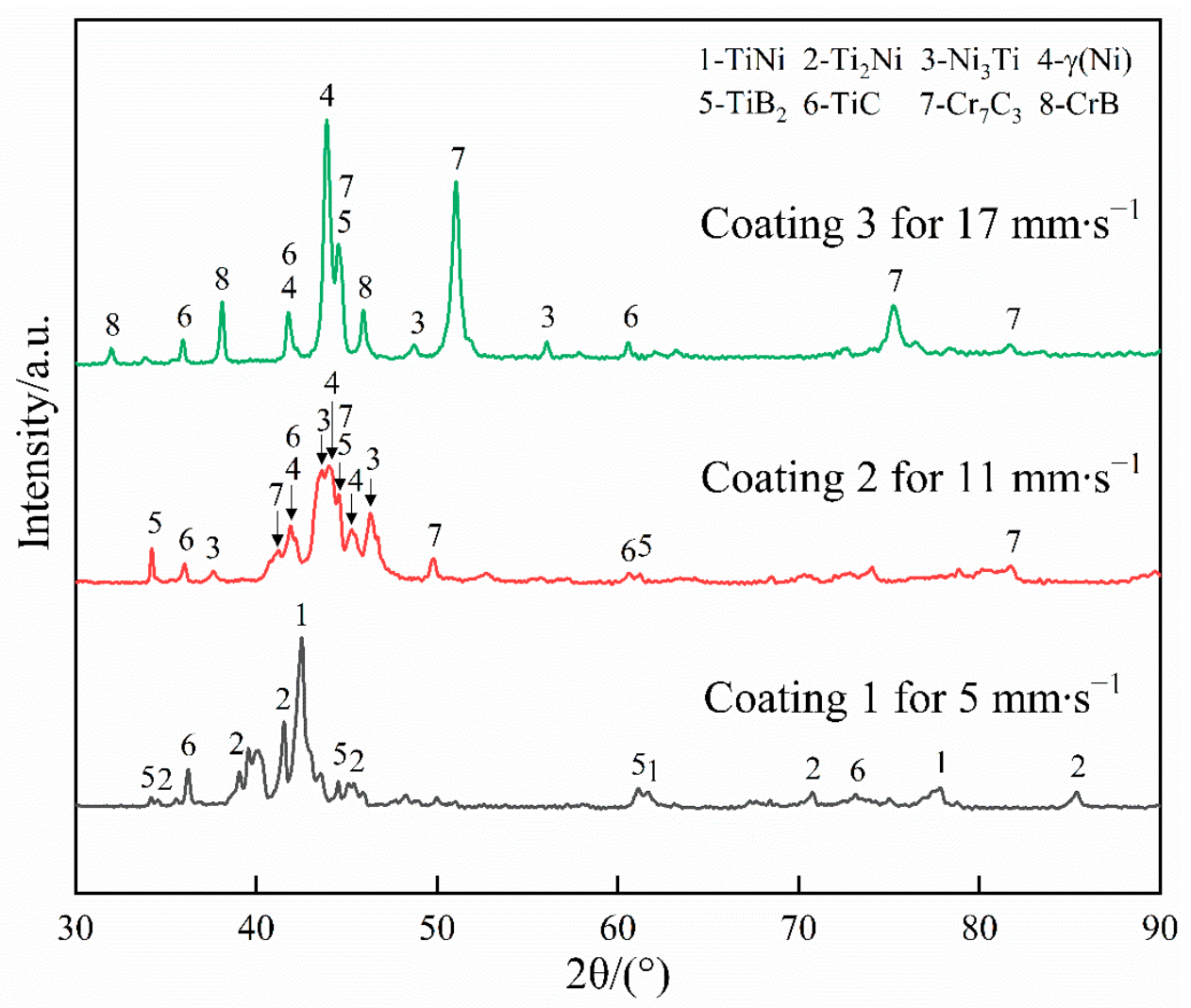

Figure 3. X-ray diffraction patterns of the coatings.

The volume fractions of different phases in the three coatings were quantitatively analyzed by Highscore Plus software (Table 1). The change in phase constituents of the coatings with the scanning speed may be expected to result in the corresponding changes in mechanical properties and corrosion resistance, as discussed below.

Table 1. The volume fractions of different phases in the coatings (vol.\%).

\begin{tabular}{ccccccccc}
\hline Coatings & $\mathbf{T i}_{\mathbf{2}} \mathbf{N i}$ & $\mathbf{T i N i}$ & $\gamma(\mathbf{N i})$ & $\mathbf{N i}_{\mathbf{3}} \mathbf{T i}$ & $\mathbf{T i B}_{\mathbf{2}}$ & $\mathbf{T i C}$ & $\mathbf{C r}_{\mathbf{7}} \mathbf{C}_{\mathbf{3}}$ & $\mathbf{C r B}$ \\
\hline 1 & 64.45 & 25.24 & - & - & 3.92 & 6.39 & - & - \\
2 & - & - & 50.37 & 30.12 & 8.39 & 4.23 & 6.89 & - \\
3 & - & - & 61.84 & 15.45 & 3.58 & 4.36 & 7.62 & 7.15 \\
\hline
\end{tabular}

The microstructures of the three coatings were observed under low magnification (Figure 4). As depicted in Figure 4a, some coarse black blocky particles with an average size of approximately $8 \mu \mathrm{m} \times 10 \mu \mathrm{m}$ are uniformly distributed in the gray matrix of Coating 1 . The gray matrix is composed of two distinct phases. Clear inspection reveals that a small number of fine dendrites adhere to the surfaces of blocky particles. As the scanning speed increased to $11 \mathrm{~mm} \cdot \mathrm{s}^{-1}$, the microstructure of Coating 2 (Figure $4 \mathrm{~b}$ ) presented a slight change relative to that of Coating 1; here, a large number of light-gray honeycomb-like structures, as well as some separated dark-gray phases, were observed. The microstructure of Coating 3 (Figure 4c) demonstrated significant differences compared with the first two coatings with further increases in the scanning speed. In this case, the blocky particles presented a downward trend in number as well as the synthesis of strip-like particles. 

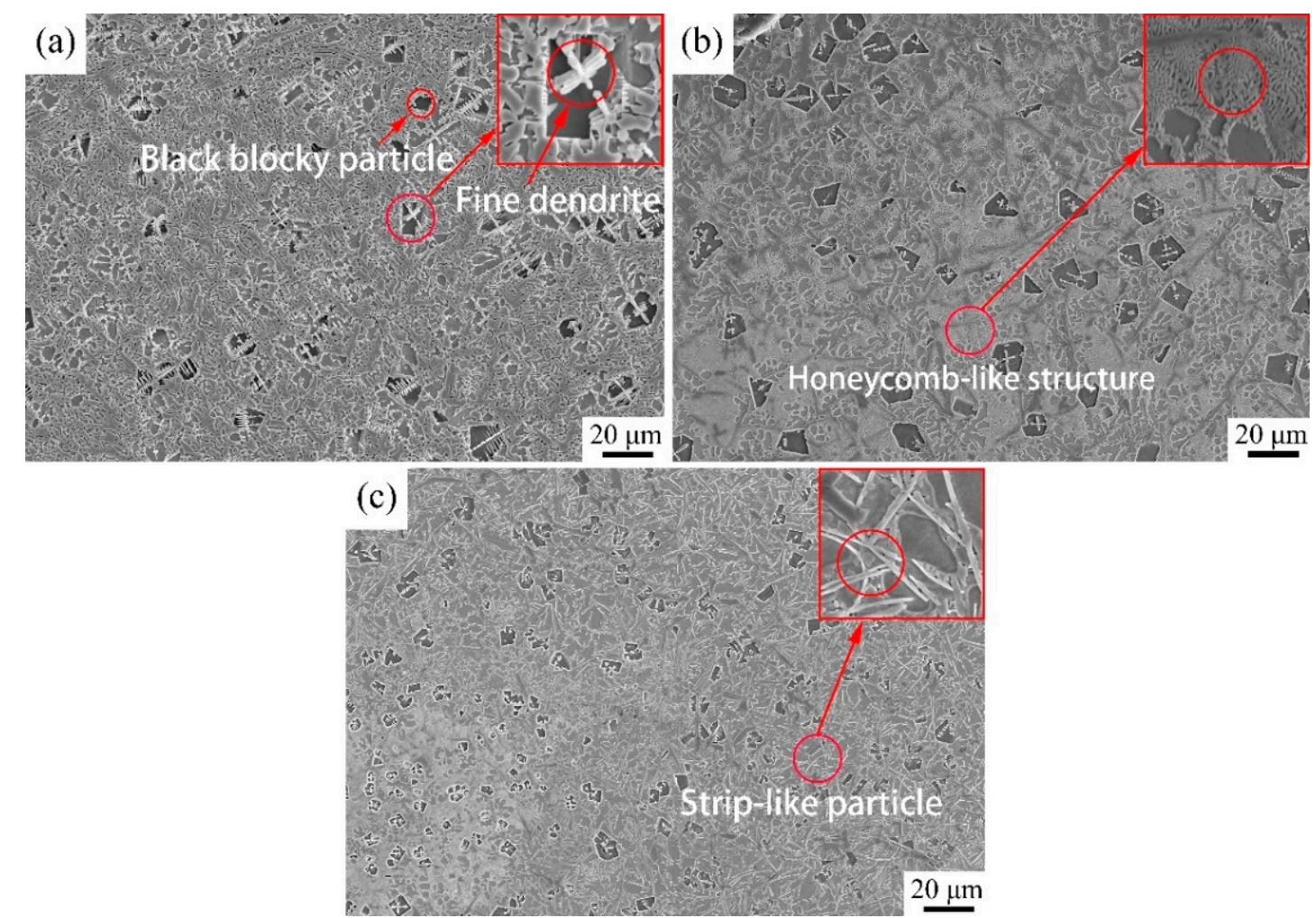

Figure 4. Microstructure of the coatings: (a) Coating 1 for $5 \mathrm{~mm} \cdot \mathrm{s}^{-1}$; (b) Coating 2 for $11 \mathrm{~mm} \cdot \mathrm{s}^{-1}$; (c) Coating 3 for $17 \mathrm{~mm} \cdot \mathrm{s}^{-1}$.

High-magnification SEM images and the corresponding EDS analyses were obtained to identify the categories and morphologies of the different phases of the coatings (Figure 5, Table 2). Coating 1 shows four phases (Figure 5(a1,a2)), which correspond to the protrusion phase (marked A), the depression phase (marked B), coarse black blocky particles (marked $\mathrm{C}$ ), and fine dendrites (marked D). The EDS analysis results indicate that Zones A and B are rich in $\mathrm{Ti}$ and $\mathrm{Ni}$; small amounts of $\mathrm{Al}$, $\mathrm{Si}$, and $\mathrm{Cr}$ could also be detected. Combining these findings with the XRD results, the two phases may be concluded to be two secondary solid solutions with Ti-N compounds as the solvent and $\mathrm{Al}, \mathrm{Si}$, and $\mathrm{Cr}$ as the solute. $\mathrm{Cr}$ and $\mathrm{Al}$ are closer to $\mathrm{Ti}$ and $\mathrm{Si}$ is closer to $\mathrm{Ni}$ in terms of atomic radius and electronegativity (atomic radius: $1.85,1.82$, and $2.00 \AA$ for $\mathrm{Cr}, \mathrm{Al}$, and $\mathrm{Ti}$, respectively; 1.46 and $1.62 \AA$ for $\mathrm{Si}$ and $\mathrm{Ni}$, respectively; electronegativity: $1.66,1.61$, and 1.54 for $\mathrm{Cr}, \mathrm{Al}$, and $\mathrm{Ti}$, respectively; 1.90 and 1.92 for $\mathrm{Si}$ and $\mathrm{Ni}$, respectively). Therefore, $\mathrm{Cr}$ and $\mathrm{Al}$ atoms could substitute $\mathrm{Ti}$ atoms, while Si atoms could displace Ni atoms in the lattices of the Ti-N compounds. The calculation results demonstrate that the atomic ratios of $\mathrm{Ti}+\mathrm{Cr}+\mathrm{Al}$ and $\mathrm{Ni}+\mathrm{Si}$ in Zones $\mathrm{A}$ and $\mathrm{B}$ are 2.1:1 and 0.9:1, respectively. The two phases could be identified as $\mathrm{Ti}_{2} \mathrm{Ni}$ and TiNi secondary solid solutions. Zone $\mathrm{C}$ is rich in $\mathrm{Ti}$ and $\mathrm{B}$, and Zone $\mathrm{D}$ mainly consists of $\mathrm{Ti}$ and $\mathrm{C}$. The black blocky phase and fine dendrites are likely $\mathrm{TiB}_{2}$ and $\mathrm{TiC}$. These results correspond well with those obtained from the XRD analyses. In addition to blocky $\mathrm{TiB}_{2}$ particles and fine $\mathrm{TiC}$ dendrites, a new coarse strip-like phase (marked $\mathrm{G}$ ) was synthesized in Coating 2 (Figure 5(b1,b2)). The reinforcement is rich in $\mathrm{C}$ and $\mathrm{Cr}$ and was determined to be $\mathrm{Cr}_{7} \mathrm{C}_{3}$ via the XRD results. In addition to the equiaxed phase (marked E), a honeycomb-like structure (marked F) was also synthesized in the matrix; this structure was not observed in Coating 1. A magnified backscattered electron (BSE) image of Zone F indicates that the honeycomb-like structure is mainly composed of light-gray reticular phases, among which a small number of dark-gray phases are located. The dark-gray and equiaxed phases have approximately the same atomic number contrast, which implies that they belong to a single phase. Zone E contains a large amount of Ni of approximately 
60 at.\%, which is slightly higher than that in the honeycomb-like structure (approximately 54 at.\%). Combining the XRD results with the Ti-Ni binary phase diagram, the equiaxed phase may be concluded to be primary $\gamma(\mathrm{Ni})$, and the honeycomb-like structure can be identified as the eutecticum of $\gamma(\mathrm{Ni})+\mathrm{Ni}_{3} \mathrm{Ti}$. When the scanning speed is increased to $17 \mathrm{~mm} \cdot \mathrm{s}^{-1}$, the volume fraction of $\gamma(\mathrm{Ni})$ gradually increases, and the volume fraction of the eutecticum correspondingly decreases. This change may be mainly associated with the increase in $\mathrm{Ni}$ content in the coatings due to weaker dilution at higher scanning speeds. Other fine strip-like particles (marked $\mathrm{H}$ ) rich in $\mathrm{Cr}$ and $\mathrm{B}$ appeared to be in situ synthesized in Coating 3 (Figure 5(c1,c2)); these particles were identified as CrB by XRD. The area fractions of these phases are shown in Table 3. It can be seen that the results are approximately similar to those shown in Table 1 . The slight changes should be attributed to the differences in the used unit; namely, the used units in Tables 1 and 3 are the volume fraction and the area fraction, respectively.
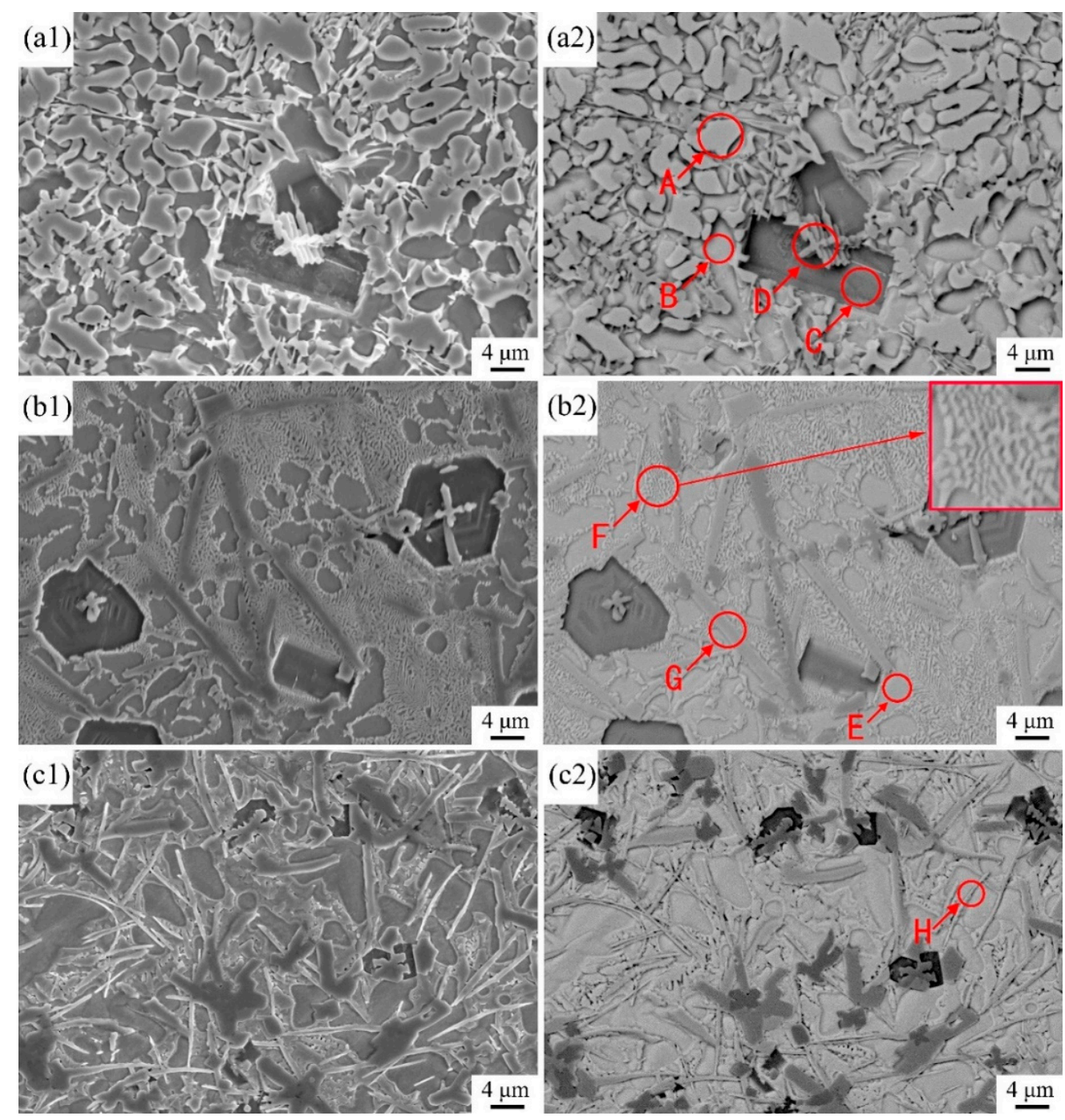

Figure 5. SEM and BSE image of cross-sectional microstructure of the coatings: $(\mathbf{a} 1, \mathbf{a} 2)$ Coating 1 for $5 \mathrm{~mm} \cdot \mathrm{s}^{-1} ;(\mathbf{b 1}, \mathbf{b} 2)$ Coating 2 for $11 \mathrm{~mm} \cdot \mathrm{s}^{-1} ;(\mathbf{c} 1, \mathbf{c} 2)$ Coating 3 for $17 \mathrm{~mm} \cdot \mathrm{s}^{-1}$. 
Table 2. EDS results of different zones in the coatings in Figure 5 (at.\%).

\begin{tabular}{|c|c|c|c|c|c|c|c|c|c|c|}
\hline \multirow{2}{*}{ Figure 5} & \multirow{2}{*}{ Coatings } & \multirow{2}{*}{$\begin{array}{l}\text { Marked } \\
\text { Zones }\end{array}$} & \multirow{2}{*}{$\begin{array}{c}\text { Corresponding } \\
\text { Phases }\end{array}$} & \multicolumn{7}{|c|}{ Elements } \\
\hline & & & & B & $\mathrm{C}$ & Al & Si & $\mathrm{Ti}$ & $\mathrm{Cr}$ & $\mathrm{Ni}$ \\
\hline \multirow{4}{*}{ (a2) } & \multirow{4}{*}{1} & A & protrusion phase & - & - & 3.81 & 6.18 & 55.46 & 8.25 & 26.3 \\
\hline & & B & depression phase & - & - & 2.40 & 2.22 & 37.66 & 6.62 & 51.10 \\
\hline & & $\mathrm{C}$ & black blocky particle & 75.92 & - & - & - & 24.08 & - & - \\
\hline & & $\mathrm{D}$ & dendrite & - & 67.41 & - & - & 32.59 & - & - \\
\hline \multirow{3}{*}{ (b2) } & \multirow{3}{*}{2} & $\mathrm{E}$ & equiaxed phase & - & - & 7.82 & 5.92 & 23.18 & 3.49 & 59.59 \\
\hline & & $\mathrm{F}$ & $\begin{array}{l}\text { honeycomb-like } \\
\text { structure }\end{array}$ & - & - & 1.67 & 8.25 & 19.39 & 16.28 & 54.41 \\
\hline & & G & $\begin{array}{c}\text { coarse strip-like } \\
\text { phase }\end{array}$ & - & 44.39 & - & - & - & 55.61 & - \\
\hline (c2) & 3 & $\mathrm{H}$ & $\begin{array}{l}\text { fine strip-like } \\
\text { particles }\end{array}$ & 83.77 & - & - & - & - & 16.23 & - \\
\hline
\end{tabular}

Table 3. The area fraction of different phases in the coatings (ar.\%).

\begin{tabular}{ccccccccc}
\hline Coatings & $\mathbf{T i}_{\mathbf{2}} \mathbf{N i}$ & $\mathbf{T i N i}$ & $\gamma(\mathbf{N i})$ & $\mathbf{N i}_{3} \mathbf{T i}$ & $\mathbf{T i B}_{\mathbf{2}}$ & $\mathbf{T i C}$ & $\mathbf{C r}_{7} \mathbf{C}_{\mathbf{3}}$ & $\mathbf{C r B}$ \\
\hline 1 & 56.50 & 30.00 & - & - & 6.56 & 6.94 & - & - \\
2 & - & - & 58.57 & 21.92 & 10.64 & 5.34 & 3.53 & - \\
3 & - & - & 69.38 & 10.84 & 6.96 & 5.01 & 7.81 & - \\
\hline
\end{tabular}

\subsection{Mechanical Properties}

\subsubsection{Microhardness Distribution along the Depth Direction of the Coatings}

The microhardness distribution along the cross-sections of the coatings is indicated in Figure 6. The cross-sections are classified into three zones on the basis of the observed changes in microhardness, namely the coating, the transition zone, and the substrate. The average microhardness of the coatings is between 877.3 and $1030.5 \mathrm{HV}_{0.2}$, which is enhanced by approximately $144 \%-186 \%$ compared with that of the substrate $\left(\approx 360 \mathrm{HV}_{0.2}\right)$. This significant improvement in microhardness is mainly attributed to the dispersive strengthening provided by a large number of in situ synthesized reinforcements, supersaturated solid solution, and fine-grain strengthening from the rapid heating and cooling of the laser cladding. This result also means that the soft substrate may be endowed with excellent resistance to microcutting during wear via the laser cladding of a hard coating. The microhardness of the coatings shows slight fluctuations, thus implying that the microstructures are comparatively uniform throughout the whole zone. Close observation reveals that the thickness of the coatings presents a downward trend with increasing scanning speed from 2.290 to $1.700 \mathrm{~mm}$ and then to $1.120 \mathrm{~mm}$. However, the average microhardness first increases and then decreases. The average microhardness is approximately $877.3 \mathrm{HV}_{0.2}$ for Coating 1, increases to $1030.5 \mathrm{HV}_{0.2}$ for Coating 2, and then decreases to $975.2 \mathrm{HV}_{0.2}$ for Coatings 3 . The phenomenon is closely associated with the change in volume fraction and category of the reinforcements with increasing scanning speed. As the scanning speed increases, the change in phase constituents of the coatings may be described as follows: $\mathrm{Ti}_{2} \mathrm{Ni}\left(56.50\right.$ ar.\%) + TiNi $(30.00 \mathrm{ar} . \%)+\mathrm{TiB}_{2}(6.56 \mathrm{ar} . \%)+\mathrm{TiC}(6.94 \mathrm{ar} . \%)$ for Coating 1 $\rightarrow \mathrm{Ni}_{3} \mathrm{Ti}\left(21.92\right.$ ar.\%) $+\gamma(\mathrm{Ni})\left(58.57\right.$ ar.\%) $+\mathrm{TiB}_{2}\left(10.64\right.$ ar.\%) $+\mathrm{TiC}\left(5.34\right.$ ar.\%) $+\mathrm{Cr}_{7} \mathrm{C}_{3}$ (3.53 ar.\%) for Coating $2 \rightarrow \mathrm{Ni}_{3} \mathrm{Ti}\left(10.84\right.$ ar.\%) $+\gamma(\mathrm{Ni})\left(69.38\right.$ ar.\%) $+\mathrm{TiB}_{2}(6.96$ ar.\%) + $\mathrm{TiC}$ (5.01 ar.\%) $+\mathrm{Cr}_{7} \mathrm{C}_{3} / \mathrm{CrB}\left(7.81\right.$ ar.\%) for Coating 3. The microhardness of $\mathrm{Ti}_{2} \mathrm{Ni}$, TiNi, $\mathrm{TiB}_{2}, \mathrm{TiC}, \mathrm{TiNi}_{3}, \gamma(\mathrm{Ni}), \mathrm{Cr}_{7} \mathrm{C}_{3}$, and $\mathrm{CrB}$ in the coatings was tested by applying a small load of $10 \mathrm{gf}$ and was found to be 616.9, 387.5, 2208.0, 1713.7, 831.2, 617.1, 1238.5, and $1409.0 \mathrm{HV}_{0.01}$, respectively. Coating 1 reveals the highest area fraction of matrix phases, the microhardness of which is fairly low. Thus, the microhardness of this coating is also low. When the scanning speed is increased to $11 \mathrm{~mm} \cdot \mathrm{s}^{-1}$, the matrix phases are transformed 
into $\gamma(\mathrm{Ni})$ and $\mathrm{Ni}_{3} \mathrm{Ti}$, which have higher microhardness, and more $\mathrm{TiB}_{2}$ with excellent microhardness is synthesized in Coating 2; thus, the average microhardness of this coating dramatically increases to $1030.5 \mathrm{HV}_{0.2}$. The ratio of the area fractions of the matrix phases and reinforcements is nearly unchanged between Coating 2 and Coating 3; however, the area fraction of $\gamma(\mathrm{Ni})$, with a low microhardness, increases, whereas that of $\mathrm{TiB}_{2}$ decreases in Coating 3. Hence, the average microhardness of Coating 3 is reduced to a certain extent compared with that of Coating 2.

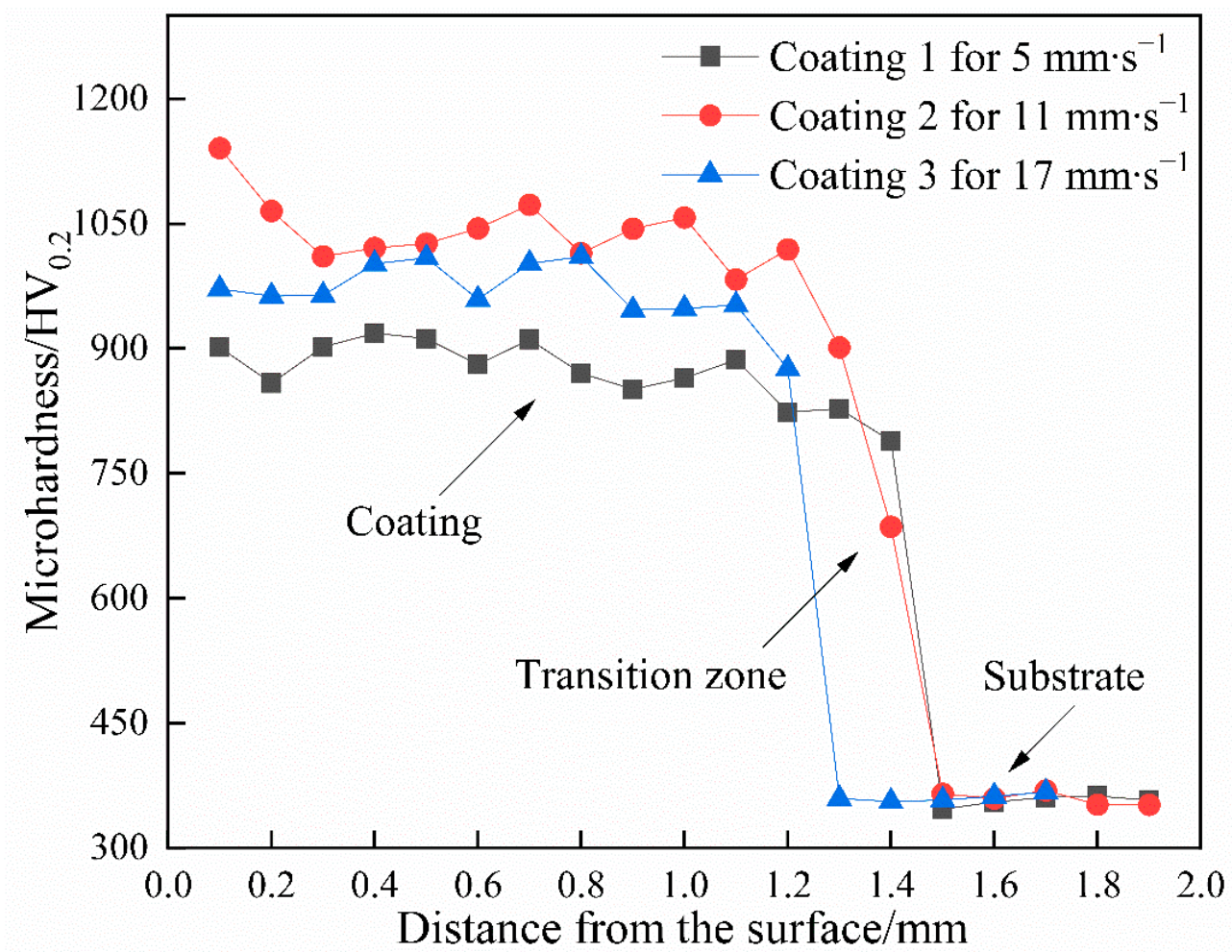

Figure 6. The microhardness distribution along the cross-sections of the coatings.

\subsubsection{Fracture Toughness of the Coatings}

Figure 7 indicates the morphologies of indentations prepared on the cross-sections of the coatings. Some cracks could clearly be observed around the angles of the indentations because the strong stress concentration generated at these angles cannot be sufficiently released by plastic deformation. According to Equation (1), the fracture toughness of the coatings could be calculated as shown in Table 4 . The average fracture toughness values of Coatings 1,2 , and 3 are $4.813,4.428$, and $5.448 \mathrm{MPa} \cdot \mathrm{m}^{1 / 2}$, respectively, thereby indicating that the cracking susceptibility of the coatings first decreases and then increases with increasing scanning speed. This change trend contradicts the change trend of microhardness.

Table 4. The fracture toughness of the coatings.

\begin{tabular}{ccccc}
\hline Coatings & \multicolumn{3}{c}{} & Average Value \\
\hline 1 & 4.697 & 4.607 & 5.136 & 4.813 \\
2 & 4.488 & 4.112 & 4.684 & 4.428 \\
3 & 5.371 & 5.286 & 5.688 & 5.448 \\
\hline
\end{tabular}



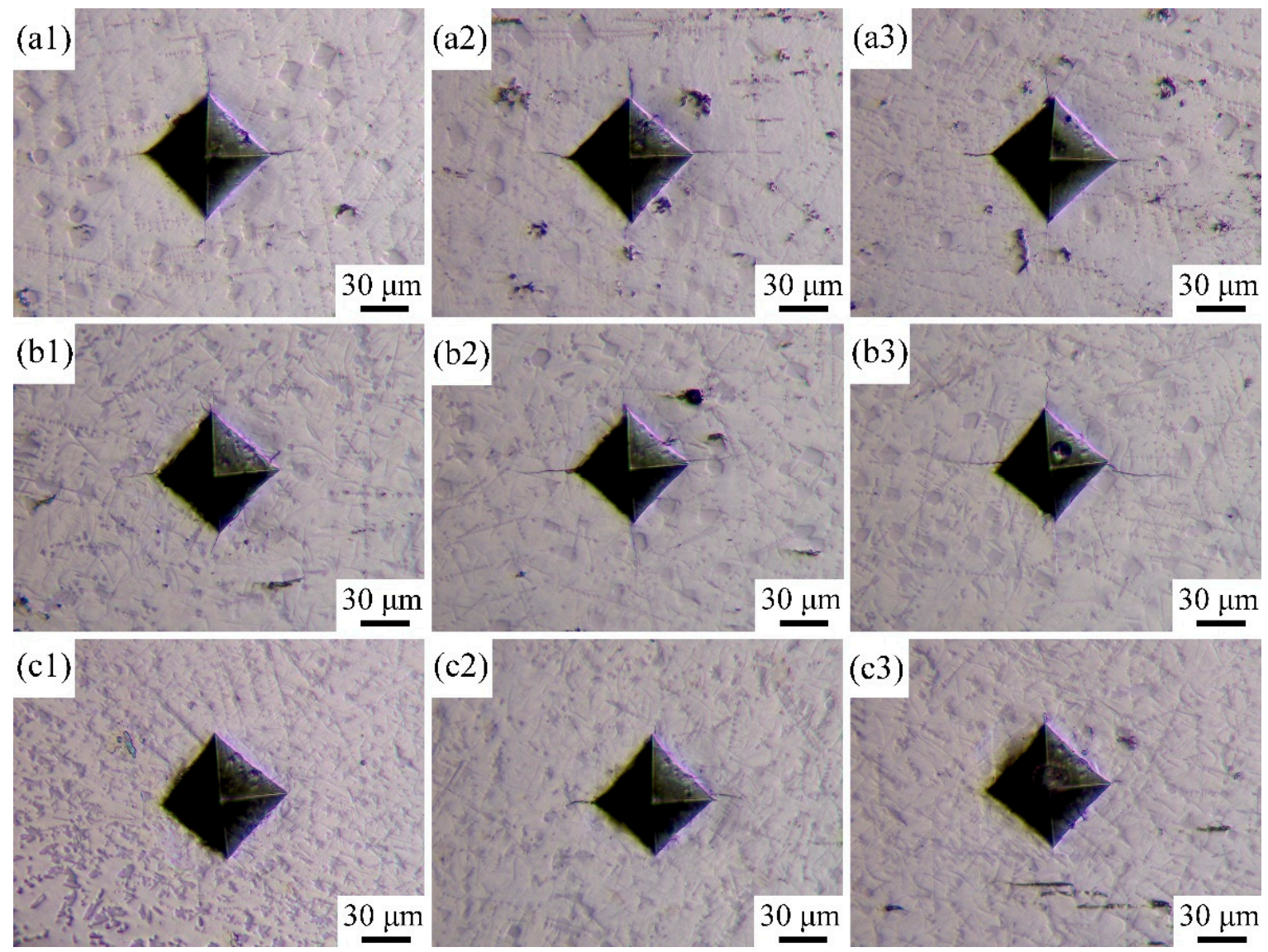

Figure 7. OM images of the indentations of the coatings: (a1-a3) Coating 1 for $5 \mathrm{~mm} \cdot \mathrm{s}^{-1}$; (b1-b3) Coating 2 for $11 \mathrm{~mm} \cdot \mathrm{s}^{-1}$; (c1-c3) Coating 3 for $17 \mathrm{~mm} \cdot \mathrm{s}^{-1}$.

\subsubsection{Corrosion Wear Resistance}

Figure 8 illustrates the friction coefficient of the coatings and substrate as a function of sliding time in $3.5 \mathrm{wt} . \% \mathrm{NaCl}$ solution. Compared with that of the coatings, the friction coefficient of the substrate changes more obviously with prolonging the sliding time. The average friction coefficient of the substrate, at approximately 0.729 , is also much higher than those of the coatings. The average friction coefficients of Coatings 1 and 2 are 0.511 and 0.537 , respectively. When the scanning speed is increased to $17 \mathrm{~mm} \cdot \mathrm{s}^{-1}$, the average friction coefficient of Coating 3 is reduced to 0.338 . This change may be related to the increase in area fraction of $\gamma(\mathrm{Ni})$ with increasing scanning speed. These results imply that the coatings produced on Ti6Al4V may show antifriction effects to a certain extent. The representative wear profiles of those samples are shown in Figure 9. The test results indicate that the average wear volumes of the substrate and coatings are 8.3017 (Substrate), 0.2417 (Coating 1), 0.1163 (Coating 2), and $0.1364 \mathrm{~mm}^{3}$ (Coating 3); the corresponding wear rates are $7.69 \times 10^{-4}$ (Substrate), $2.24 \times 10^{-5}$ (Coating 1), $1.08 \times 10^{-5}$ (Coating 2), and $1.26 \times 10^{-5} \mathrm{~mm}^{3} \cdot \mathrm{N}^{-1} \cdot \mathrm{m}^{-1}$ (Coating 3). The average wear rate of the coating (approximately $1.53 \times 10^{-5} \mathrm{~mm}^{3} \cdot \mathrm{N}^{-1} \cdot \mathrm{m}^{-1}$ ) is significantly reduced by $98.01 \%$ when compared with that of the substrate, thereby demonstrating that the coatings possess outstanding wear resistance. The wear volume of the coatings first decreased and then increased with increasing scanning speed because of the synergistic effects of microhardness and fracture toughness on wear resistance. Improvements in microhardness could endow the samples with better resistance to microcutting and reduce their wear volume. In addition, the resistance to brittle debonding decreases because of the reduction in fracture toughness, which results in an increase in wear volume. Therefore, a sample with a suitable combination of microhardness and fracture toughness may reasonably be expected to 
produce optimal wear resistance. The wear loss of Coating 1 mainly originates from microcutting because of its low microhardness. The stress concentration generated in the coating during sliding can be effectively released by plastic deformation, which means that the wear loss from brittle debonding may be negligible. When the scanning speed is enhanced to $11 \mathrm{~mm} \cdot \mathrm{s}^{-1}$, the microhardness increases from 877.3 to $1030.5 \mathrm{HV}_{0.2}$ and the fracture toughness decreases from 5.448 to 4.428 . The former reduces the wear volume because of improvements in resistance to microcutting; however, the latter produces the exact opposite effect because of the reduction in resistance to brittle debonding. Overall, the wear volume is still reduced because the former plays the dominant role in wear resistance. However, the wear loss resulting from brittle debonding is not negligible. Coating 3 , which presents a lower microhardness compared with Coating 2, demonstrates a higher wear volume, which indicates that the increase in wear loss due to reductions in the coating's resistance to microcutting cannot be sufficiently compensated by decreases in wear loss from resistance to brittle debonding.

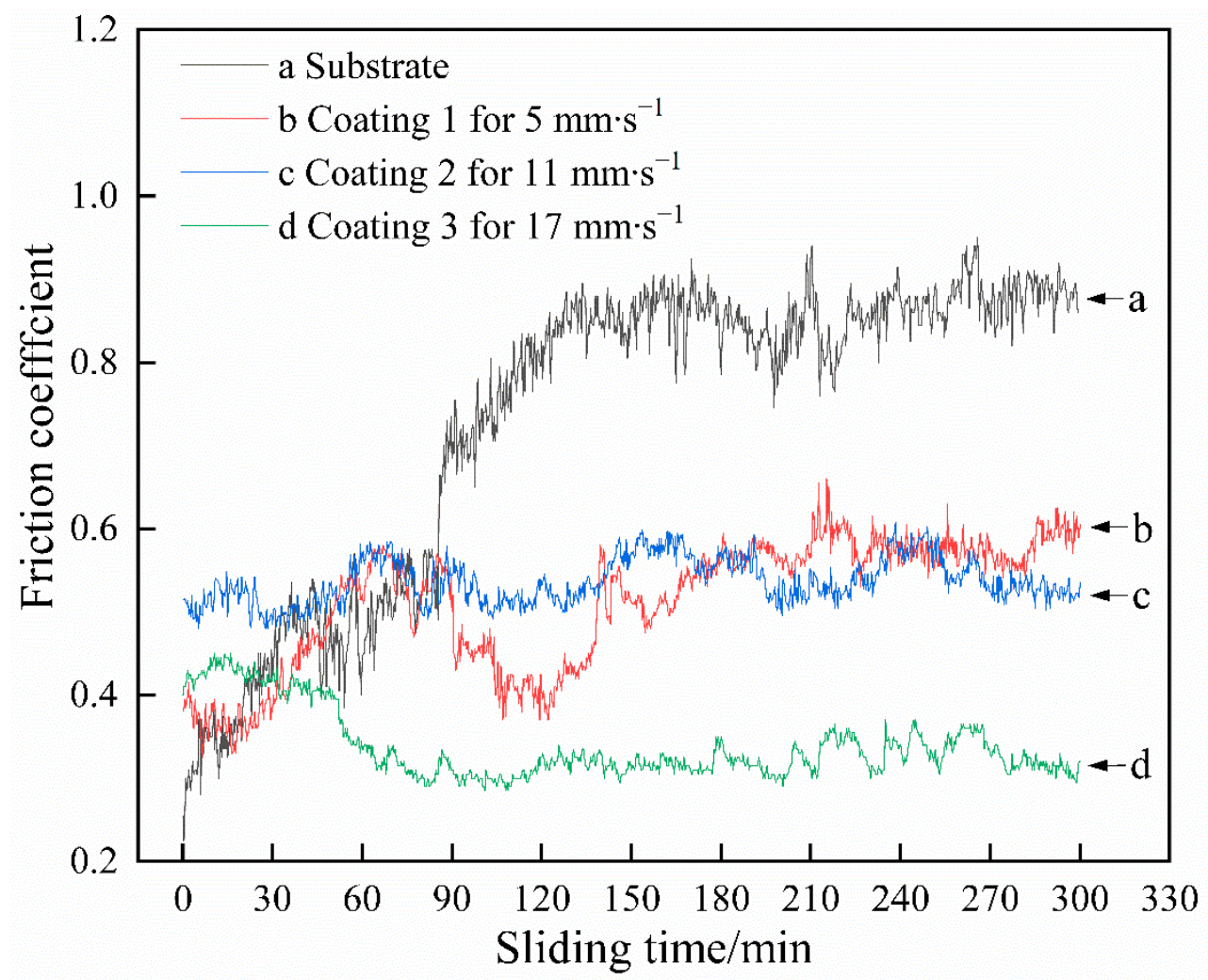

Figure 8. Variation of friction coefficient of the samples with sliding time in the $3.5 \mathrm{wt} . \% \mathrm{NaCl}$ solution.

Figure 10 illustrates the wear morphologies of the samples. As shown in Figure 10(a1,a2), a large number of furrows with different widths are distributed parallel to the sliding direction on the worn surface of the substrate. Some of these furrows may originate from microcutting due to the sharp protrusions of the counterpart $\left(\mathrm{Si}_{3} \mathrm{~N}_{4}\right)$, while others may be attributed to the plastic deformation of the substrate from the blunt protrusions of $\mathrm{Si}_{3} \mathrm{~N}_{4}$. Several blocky dark-gray substances, which are mainly composed of Ti and $\mathrm{O}$ according to the EDS results, also adhere to the substrate surface. These substances reflect the debris decoupled from the substrate surface. Some debris particles cluster together and form loose films (Zone A), while others are rolled into dense films under the applied load (Zone B). According to the morphological analyses, the wear mechanism of the substrate can be identified as the combination of microcutting and oxidation. 

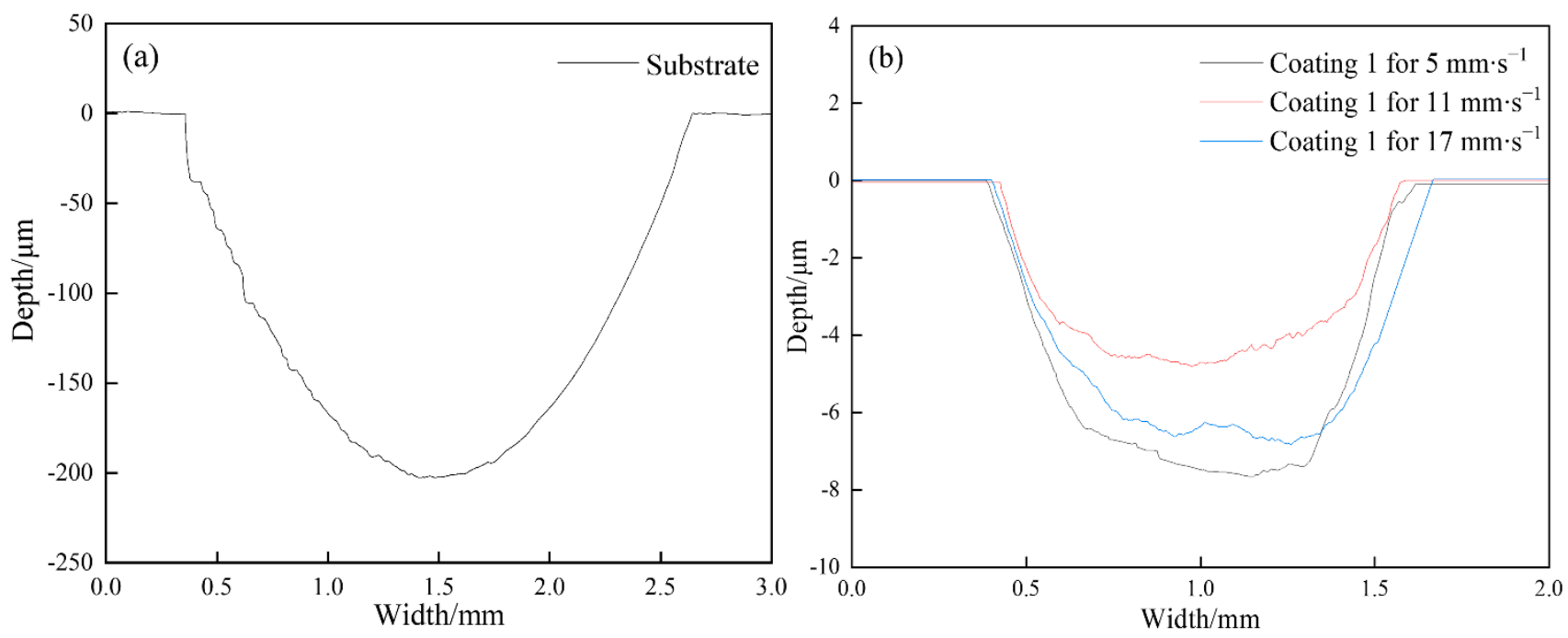

Figure 9. Representative wear profiles of substrate (a) and the coatings (b).

The worn surfaces of the coatings are considerably smoother compared with that of the substrate, which means that the coatings experience slight loss during sliding. Figure 10(b1,b2) show that partial zones of the worn surface of Coating 1 are covered with black films. These films are rich in O (64.54 at.\%), as well as elements from the coating, thereby indicating that they also originate from the debris falling off the coating surface. Clear inspection reveals that a portion of the films is exfoliated from the worn surface, leaving chipping pits with rough surfaces and clear edges. Thus, the films left on the worn surface of Coating 1 are much less than those on the worn surface of the substrate. Such a phenomenon is mainly associated with significant differences in mechanical properties between the coating and the substrate. The coating has higher microhardness and lower plasticity than the substrate, which means that debris is more likely to be embedded into the substrate surface and rolled into denser films with stronger bonding ability to the substrate. The brittle films composed of the coating debris tend to break into fragments and debond from the worn surface. In addition to adherent films and chipping pits, a small number of fine furrows can be observed on the worn surface of the coating. Therefore, the wear mechanism of this coating involves the combination of slight microcutting, oxidation, and brittle debonding. Compared with that of Coating 1, the worn surface of Coating 1 presents remarkable differences (Figure 10(c1,c2)). Intact and thick films are difficult to form on the worn surface because of the high microhardness and low fracture toughness of Coating 2. Furrows could barely be observed, which means that this coating is strongly resistant to microcutting. Some coarse cracks are initiated and propagate along the worn surface, and many fine cracks are observed in the inner regions of the blocky TiB particles, which is likely due to the high cracking susceptibility of Coating 2. Sliding produces high levels of stress concentration in $\mathrm{TiB}_{2}$ particles, and this stress cannot easily be released by the plastic deformation of the matrix because of its low plasticity. Consequently, cracks are initiated and propagate in the inner region of $\mathrm{TiB}_{2}$ particles and the interface between $\mathrm{TiB}_{2}$ and the matrix, which may cause brittle debonding of the coating. Therefore, the wear mechanism of Coating 2 involves the combination of minimal microcutting, oxidation, and moderate brittle debonding. The surface wear morphology of Coating 3 (Figure 10(d1,d2)) is very similar to that of Coating 1 , thereby implying that the wear loss in Coating 3 mainly originates from slight microcutting and oxidation owing to its relatively low microhardness. Thus, considering that the results of corrosion wear are concerning, $11 \mathrm{~mm} \cdot \mathrm{s}^{-1}$ is the optimal scanning speed to prepare Ni-based coatings on Ti6Al4V by laser cladding. 

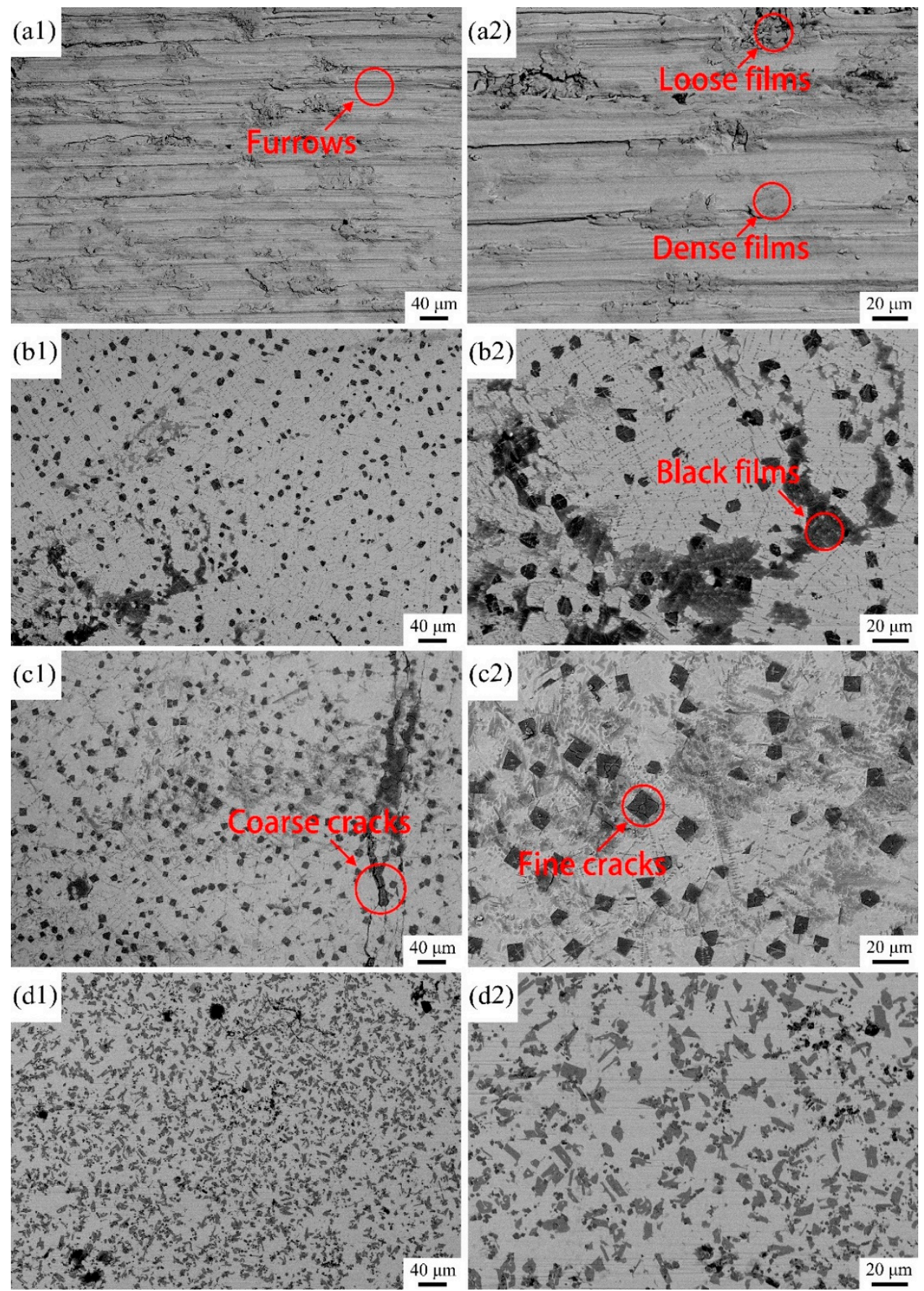

Figure 10. BSE images of the worn morphologies of the samples: $(\mathbf{a} 1, \mathbf{a} 2)$ substrate; $(\mathbf{b} 1, \mathbf{b} 2)$ Coating 1 for $5 \mathrm{~mm} \cdot \mathrm{s}^{-1}$; (c1,c2) Coating 2 for $11 \mathrm{~mm} \cdot \mathrm{s}^{-1} ;(\mathbf{d} 1, \mathbf{d} 2)$ Coating 3 for $17 \mathrm{~mm} \cdot \mathrm{s}^{-1}$.

\subsection{Corrosion Performance}

Figure 11 shows the potentiodynamic polarization curves of the coatings and substrate in $3.5 \mathrm{wt} . \% \mathrm{NaCl}$ solution. Some parameters (Table 5$)$, such as corrosion potential ( $\left.\mathrm{E}_{\text {corr }}\right)$, corrosion current density $\left(\mathrm{i}_{\text {corr }}\right)$, and current density $\left(\mathrm{i}_{\mathrm{s}}\right)$ in the active and comparatively stable corrosion state can be acquired from Figure 11. 

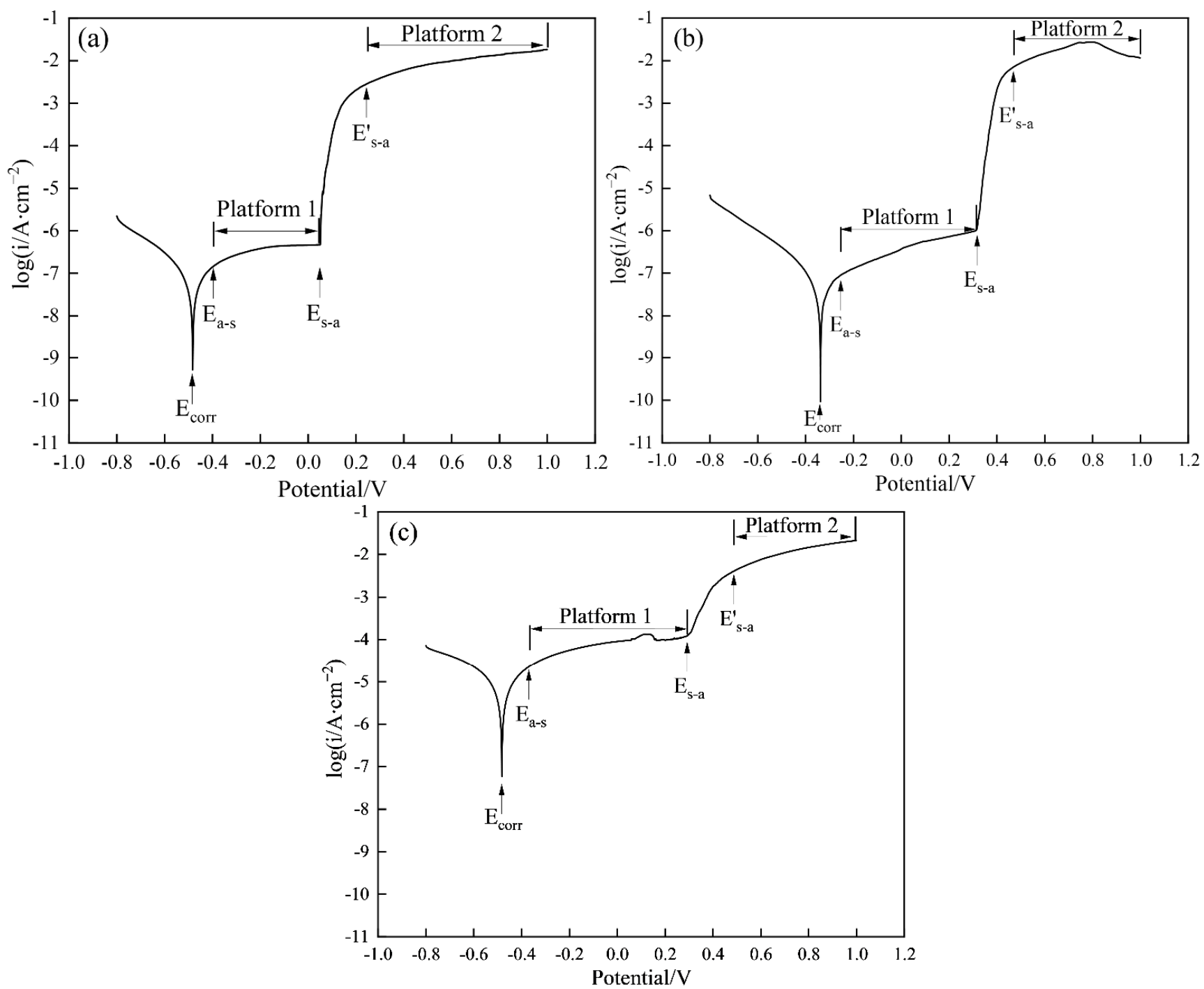

Figure 11. Potentiodynamic polarization curves of the Coatings in the $3.5 \mathrm{wt} . \% \mathrm{NaCl}$ solution ((a) Coating 1 for $5 \mathrm{~mm} \cdot \mathrm{s}^{-1}$; (b) Coating 2 for $11 \mathrm{~mm} \cdot \mathrm{s}^{-1}$; (c) Coating 3 for $17 \mathrm{~mm} \cdot \mathrm{s}^{-1}$ ).

Table 5. Electrochemical parameters obtained from Figure 11.

\begin{tabular}{ccccccccc}
\hline Coatings & $\mathbf{E}_{\text {corr }} / \mathbf{V}$ & $\mathbf{E}_{\mathbf{a}-\mathbf{s}} / \mathbf{V}$ & $\mathbf{E}_{\mathbf{a}-\mathbf{s}}-\mathbf{E}_{\text {corr }} / \mathbf{V}$ & $\mathbf{E}_{\text {s-a }} / \mathbf{V}$ & $\mathbf{E}_{\mathbf{a} \text {-s }}^{\prime} / \mathbf{V}$ & $\mathbf{i}_{\text {corr }} / \mathbf{A} \cdot \mathbf{c m}^{-2}$ & $\mathbf{i}_{\mathbf{s}} / \mathbf{A} \cdot \mathbf{c m}^{-2}$ & $\mathbf{i}^{\prime} \mathbf{s} / \mathbf{A} \cdot \mathbf{c m}^{-2}$ \\
\hline 1 & -0.483 & -0.402 & 0.081 & 0.050 & 0.242 & $8.435 \times 10^{-8}$ & $3.500 \times 10^{-7}$ & $9.311 \times 10^{-3}$ \\
2 & -0.338 & -0.290 & 0.048 & 0.313 & 0.464 & $6.715 \times 10^{-8}$ & $3.644 \times 10^{-7}$ & $1.209 \times 10^{-2}$ \\
3 & -0.483 & -0.321 & 0.162 & 0.290 & 0.486 & $8.806 \times 10^{-6}$ & $7.345 \times 10^{-5}$ & $1.140 \times 10^{-2}$ \\
\hline
\end{tabular}

Among the coatings obtained, Coating 2 possesses the most positive $\mathrm{E}_{\mathrm{corr}}$. $\mathrm{E}_{\mathrm{corr}}$ refers to the potential at which the material reaches a stable corrosion state; this parameter can be applied to characterize the tendency of a material to corrode in a corrosion system. A material with low $\mathrm{E}_{\text {corr }}$ is more inclined to act as a cathode in a galvanic cell without an applied voltage and suffer from serious corrosion by losing electrons when compared with that with a high $\mathrm{E}_{\text {corr }}$. Therefore, in terms of $\mathrm{E}_{\text {corr }}$, Coating 2 demonstrates the best corrosion resistance among the three coatings. Coating 2 also demonstrates the lowest $\mathrm{i}_{\text {corr }}$ among the three coatings. $\mathrm{i}_{\text {corr }}$, which refers to the corrosion current density at $\mathrm{E}_{\text {corr }}$, is used to characterize the corrosion rate of a material. Therefore, in terms of $i_{\text {corr, }}$, the corrosion resistance of Coating 2 is also superior to those of Coatings 1 and 3 . Changes in $\mathrm{E}_{\text {corr }}$ and $\mathrm{i}_{\text {corr }}$ may be attributed to differences in the composition and phases of the 
samples. When the applied potential exceeds $E_{\text {corr }}$, the electrode surface enters the active state because $i_{s}$ rapidly increases as the potential increases. These phenomena promote oxidation reactions on the electrode surface, which releases metals in their ionic form to the electrolyte. As the potential further increases, $i_{s}$ increases slowly and finally reaches a comparatively stable value, thus indicating that the electrode enters a comparatively stable corrosion state. The transformation from active state to comparatively stable corrosion state is closely related to the formation of a thin and dense oxidation film formed on the electrode surface, which isolates the material from the electrode and greatly retards the release rate of metal ions. The formation preference of the passive film can be evaluated by assessing differences between $\mathrm{E}_{\text {corr }}$ and the critical potential $\left(\mathrm{E}_{\mathrm{a}-\mathrm{s}}\right)$ as the electrode transforms from the active state to the comparatively stable corrosion state. As shown in Table 5, the $E_{a-s}-E_{\text {corr }}$ values of the coatings show the trend Coating $3>$ Coating $1>$ Coating 2, thus indicating that the oxidation film is more easily formed on the surface of Coating 2 than on the surfaces of the two other coatings. The corrosion rate in the comparatively stable corrosion state can be described by $i_{s}$, which is the average value of all current densities obtained in Platform 1, as shown in Figure 11. The results of $i_{\mathrm{s}}$ demonstrated the following order: Coating $2\left(3.664 \times 10^{-7} \mathrm{~A} \cdot \mathrm{cm}^{-2}\right) \approx$ Coating $1\left(3.500 \times 10^{-7} \mathrm{~A} \cdot \mathrm{cm}^{-2}\right)$ $<$ Coating $3\left(7.345 \times 10^{-5} \mathrm{~A} \cdot \mathrm{cm}^{-2}\right)$. These results indicate that Coating 2 possesses the lowest corrosion rate in the comparatively stable corrosion state. When the potential exceeds another critical potential $\left(E_{s-a}\right), i_{s}$ is sharply enhanced with increasing potential, thereby indicating that the electrode enters the active state once more because a portion of the oxidation film suffers from destruction. Coating 2 clearly demonstrates a higher $\mathrm{E}_{\mathrm{s}-\mathrm{a}}(0.313 \mathrm{~V})$ compared with those of Coating $1(0.050 \mathrm{~V})$ and Coating $3(0.290 \mathrm{~V})$, which means that the oxidation film formed on Coating 2 is more stable than those formed on the other coatings. Further increases in potential clearly identify a third critical potential ( $\left.E^{\prime}{ }_{s-a}\right)$, beyond which the electrode enters a second comparatively stable corrosion state because of the repair of the damaged oxidation film. The $i_{\mathrm{S}}$ of the three coatings in this state is similar (approximately $1.093 \times 10^{-2} \mathrm{~A} \cdot \mathrm{cm}^{-2}$ ), which corresponds to the average value in Platform 2. Thus, according to the above analyses, Coating 2 exhibits greater corrosion resistance than Coating 1 or Coating 3.

XPS was applied to detect the elemental composition and corresponding valences of the oxidation film formed on Coating 2 to reveal the passive mechanism of the electrode, as shown in Figure 12. Figure 12a shows the XPS survey spectrum of the oxidation film formed on Coating 2. The oxidation film is composed of $\mathrm{Ni}, \mathrm{Al}, \mathrm{Ti}, \mathrm{Cr}, \mathrm{Si}$, and $\mathrm{O}$. Then, the high-resolution narrow spectra of these metal elements were obtained to detect their valence states. Four strong peaks at 855.57, 873.21, 861.09, and $879.72 \mathrm{eV}$ were clearly detected in the $\mathrm{Ni}_{2 \mathrm{p}}$ spectrum (Figure 12b), which fit the standard peaks of $\mathrm{Ni}$ in $\mathrm{NiO}$ well. The strong peak at $74.49 \mathrm{eV}$ in the $\mathrm{Al}_{2 \mathrm{p}}$ spectrum (Figure 12c) confirms the existence of $\mathrm{Al}_{2} \mathrm{O}_{3}$. Two strong peaks at $458.43 \mathrm{eV}$ and $464.63 \mathrm{eV}$ in the $\mathrm{Ti}_{2 \mathrm{p}}$ spectrum (Figure 12d) prove the presence of $\mathrm{TiO}_{2}$ in the oxidation film. Two obvious peaks at 576.57 and $585.93 \mathrm{eV}$, which are highly consistent with the binding energies of $\mathrm{Cr}$ in $\mathrm{Cr}_{2} \mathrm{O}_{3}$, could be detected in the $\mathrm{Cr}_{2 p}$ spectrum (Figure 12e). The clear peak with a binding energy of $101.95 \mathrm{eV}$ in Figure $12 \mathrm{f}$ confirms the existence of $\mathrm{SiO}_{2}$. According to the above analyses, the oxidation film may be concluded to be mainly composed of $\mathrm{NiO}, \mathrm{Al}_{2} \mathrm{O}_{3}, \mathrm{TiO}_{2}, \mathrm{Cr}_{2} \mathrm{O}_{3}$, and $\mathrm{SiO}_{2}$. The molar fraction of oxides in the coatings can be calculated from the XPS results (Table 6). As the scanning speed increased, the contents of $\mathrm{TiO}_{2}$ and $\mathrm{Al}_{2} \mathrm{O}_{3}$ demonstrated a gradual downward trend, whereas the contents of $\mathrm{NiO}, \mathrm{Cr}_{2} \mathrm{O}_{3}$, and $\mathrm{SiO}_{2}$ revealed an upward trend due to reductions in the dilution rate of the coatings. 

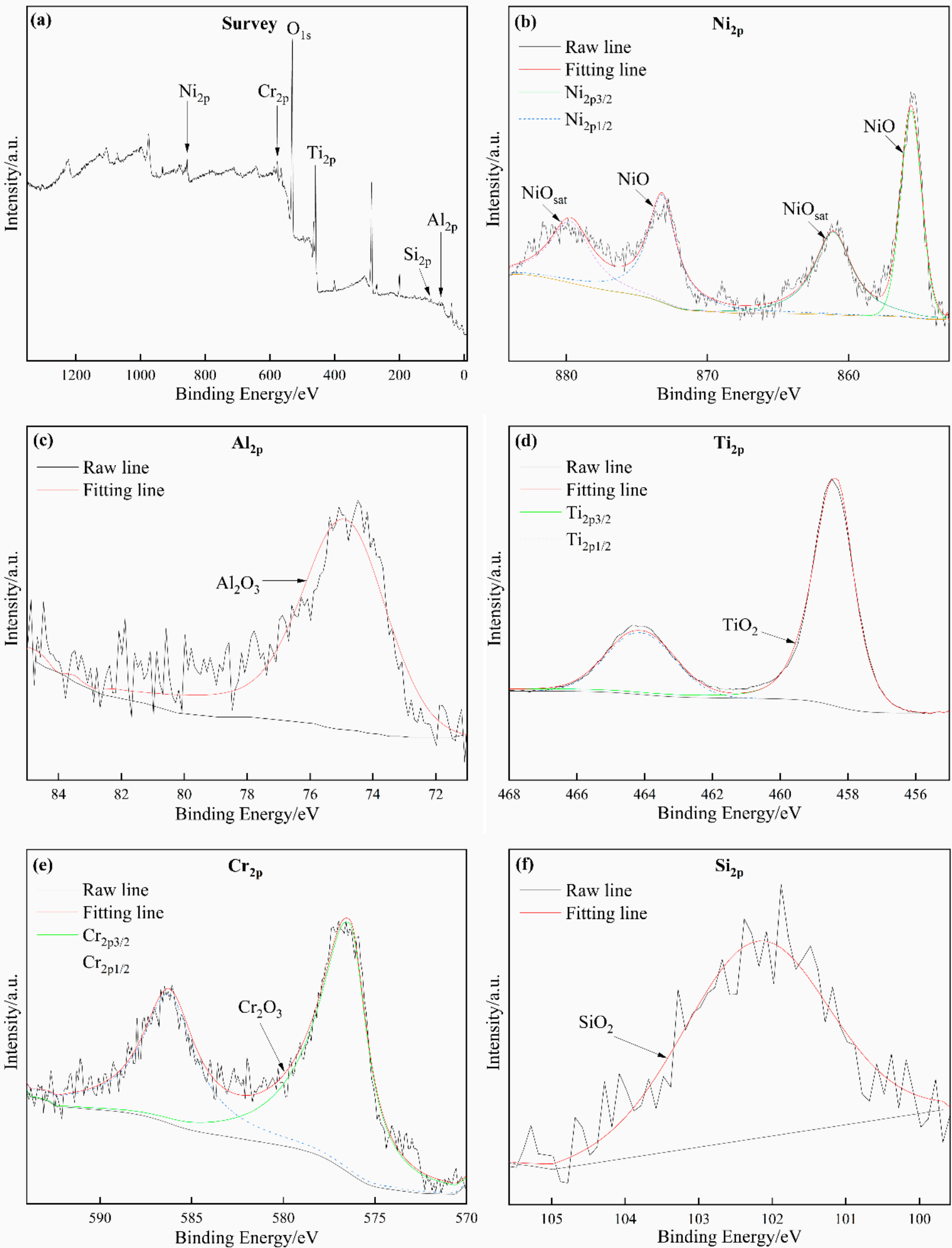

Figure 12. XPS spectra of the oxide film formed on the surface of Coating 2 for $11 \mathrm{~mm} \cdot \mathrm{s}^{-1}$ : (a) Survey; (b) $\mathrm{Ni}_{2 \mathrm{p}}$; (c) $\mathrm{Al}_{2 \mathrm{p}}$; (d) $\mathrm{Ti}_{2 p} ;(\mathbf{e}) \mathrm{Cr}_{2 p} ;(\mathbf{f}) \mathrm{Si}_{2 p}$. 
Table 6. Oxides contents in the oxidation film formed on the coatings (at.\%).

\begin{tabular}{cccccc}
\hline Coatings & $\mathrm{TiO}_{\mathbf{2}}$ & $\mathrm{Al}_{\mathbf{2}} \mathbf{O}_{\mathbf{3}}$ & $\mathbf{N i O}$ & $\mathrm{Cr}_{\mathbf{2}} \mathbf{O}_{\mathbf{3}}$ & $\mathbf{S i O}_{\mathbf{2}}$ \\
\hline 1 & 65.53 & 7.83 & 12.21 & 5.77 & 8.66 \\
2 & 40.24 & 6.16 & 16.74 & 14.49 & 22.37 \\
3 & 26.82 & 4.76 & 19.54 & 17.05 & 31.83 \\
\hline
\end{tabular}

Differences in the formation preference of the oxidation film among the samples may be reasonably explained by thermodynamic calculations. According to the XPS results, the following reactions occur during oxidation:

$$
\begin{aligned}
\mathrm{Ti}+\mathrm{O}_{2} & =\mathrm{TiO}_{2} \\
4 \mathrm{Al}+3 \mathrm{O}_{2} & =2 \mathrm{Al}_{2} \mathrm{O}_{3} \\
2 \mathrm{Ni}+\mathrm{O}_{2} & =2 \mathrm{NiO} \\
4 \mathrm{Cr}+3 \mathrm{O}_{2} & =2 \mathrm{Cr}_{2} \mathrm{O}_{3} \\
\mathrm{Si}+\mathrm{O}_{2} & =\mathrm{SiO}_{2} .
\end{aligned}
$$

The change in the standard Gibbs free energy $\left(\Delta \mathrm{G}^{\theta}\right)$ at room temperature (approximately $298 \mathrm{~K}$ ) can be calculated as $-889.53 \mathrm{KJ} \cdot \mathrm{mol}^{-1}$ for Reaction (4), $-3163.88 \mathrm{KJ} \cdot \mathrm{mol}^{-1}$ for Reaction (5), $-424.90 \mathrm{KJ} \cdot \mathrm{mol}^{-1}$ for Reaction (6), $-2096.35 \mathrm{KJ} \cdot \mathrm{mol}^{-1}$ for Reaction (7), and $-856.50 \mathrm{KJ} \cdot \mathrm{mol}^{-1}$ for Reaction (8). As the $\Delta \mathrm{G}^{\theta}$ of all reactions is negative, these reactions spontaneously occur. The reaction order in terms of thermodynamics is Reaction (5) $>$ Reaction (7) $>$ Reaction (4) $>$ Reaction (8) $>$ Reaction (6). Given the calculated results of $\Delta \mathrm{G}^{\theta}$, determining which sample the oxidation film preferentially forms on is very difficult.

The compactness of the formed oxidation film is also responsible for the formation preference of the oxidation film, which can be characterized via the Pilling-Bedworth ratio (PBR). The PBR reflects the change in volume of a given metal element $(X)$ subject to oxidation $\left(A X+B O_{2}=C X_{m} O_{n}\right)$ and could be calculated by the following formula [45]:

$$
\mathrm{PBR}=\frac{C \rho_{X} Z_{X_{m} O_{n}}}{A \rho_{X_{m} O_{n}} Z_{X}}
$$

where $A$ and $C$ refer to the molar numbers of the reactant $(X)$ and product $\left(X_{m} O_{n}\right)$, respectively, $Z_{X}$ and $Z_{X_{m} O_{n}}$ signify the atomic weight of the reactant $(X)$ and the molecular weight of the product $\left(X_{m} O_{n}\right)$, respectively, and $X$ and ${ }_{X_{m} O_{n}}$ represent the density of the reactant $(X)$ and product $\left(X_{m} O_{n}\right)$, respectively.

The PBR of the above reactions could be calculated as 1.77 for Reaction (4), 1.46 for Reaction (5), 1.66 for Reaction (6), 2.02 for Reaction (7), and 2.27 for Reaction (8). The PBRs of the above reactions are all greater than 1 , which indicates that the metal subject to oxidation undergoes volume expansion, which could improve the compactness of the oxidation film and result in better blocking effects between the sample and electrolyte. However, when the PBR is higher than 2, high levels of stress may be produced and cause cracking of the oxidation film. The electrolyte may still be in contact with the sample via the fracture areas and cause the active dissolution of these areas, thus retarding the change process from the active state to the comparatively stable corrosion state. Coatings 1 and 2 can enter into the comparatively stable corrosion state more rapidly than Coating 3 because of their low $\mathrm{E}_{\mathrm{a}-\mathrm{s}}-\mathrm{E}_{\text {corr }}$ values, which could be attributed to their suitable contents of $\mathrm{Cr}$ and $\mathrm{Si}$ with a high PBR. As the contents of $\mathrm{Cr}$ and $\mathrm{Si}$ are further enhanced in Coating 3, some cracks may be generated and delay the change process from the active state to the comparatively stable corrosion state. 


\section{Conclusions}

(1) Adjusting the scanning speed may be an effective strategy to regulate the microstructure of laser-clad coatings prepared on Ti6Al4V with NiCrBSi powder as the cladding material. The microstructure of the coating was transformed from $\mathrm{Ti}_{2} \mathrm{Ni}+\mathrm{TiNi}$ $+\mathrm{TiB}_{2}+\mathrm{TiC}$ at $5 \mathrm{~mm} \cdot \mathrm{s}^{-1}$ into primary $\gamma(\mathrm{Ni})+$ eutectics of $\left(\gamma(\mathrm{Ni})+\mathrm{Ni}_{3} \mathrm{Ti}\right)+\mathrm{TiB}_{2}+\mathrm{TiC}+$ $\mathrm{Cr}_{7} \mathrm{C}_{3}$ at $11 \mathrm{~mm} \cdot \mathrm{s}^{-1}$ and then into primary $\gamma(\mathrm{Ni})+$ eutectics of $\left(\gamma(\mathrm{Ni})+\mathrm{Ni}_{3} \mathrm{Ti}\right)+\mathrm{TiB}_{2}+\mathrm{TiC}+$ $\mathrm{Cr}_{7} \mathrm{C}_{3}+\mathrm{CrB}$ at $17 \mathrm{~mm} \cdot \mathrm{s}^{-1}$.

(2) As the scanning speed increased, the average microhardness of the coatings first increased and then decreased $\left(877.3 \mathrm{HV}_{0.2}\right.$ at $5 \mathrm{~mm} \cdot \mathrm{s}^{-1}, 1030.5 \mathrm{HV}_{0.2}$ at $11 \mathrm{~mm} \cdot \mathrm{s}^{-1}$, and $975.2 \mathrm{HV}_{0.2}$ at $17 \mathrm{~mm} \cdot \mathrm{s}^{-1}$ ). The opposite trend was noted for fracture toughness $\left(4.813 \mathrm{MPa} \cdot \mathrm{m}^{1 / 2}\right.$ at $5 \mathrm{~mm} \cdot \mathrm{s}^{-1}, 4.428 \mathrm{MPa} \cdot \mathrm{m}^{1 / 2}$ at $11 \mathrm{~mm} \cdot \mathrm{s}^{-1}$, and $5.448 \mathrm{MPa} \cdot \mathrm{m}^{1 / 2}$ at $\left.17 \mathrm{~mm} \cdot \mathrm{s}^{-1}\right)$.

(3) The optimum combination of microhardness and wear resistance was acquired in the coating prepared at $11 \mathrm{~mm} \cdot \mathrm{s}^{-1}$. This coating showed outstanding wear resistance in $3.5 \mathrm{wt} . \% \mathrm{NaCl}$ solution (wear rate, $1.08 \times 10^{-5} \mathrm{~mm}^{3} \cdot \mathrm{N}^{-1} \cdot \mathrm{m}^{-1}$ ) compared with the other coatings (Coating 1, $2.24 \times 10^{-5} \mathrm{~mm}^{3} \cdot \mathrm{N}^{-1} \cdot \mathrm{m}^{-1}$; Coating 3, $1.26 \times 10^{-5} \mathrm{~mm}^{3} \cdot \mathrm{N}^{-1} \cdot \mathrm{m}^{-1}$ ).

(4) Coating 2 demonstrated the best corrosion resistance among the coatings synthesized. Specifically, this sample showed the highest $\mathrm{E}_{\text {corr }}(-0.338 \mathrm{~V})$, lowest $\mathrm{i}_{\text {corr }}$ $\left(6.715 \times 10^{-8} \mathrm{~A} \cdot \mathrm{cm}^{-2}\right)$, and low i $\mathrm{i}_{\mathrm{s}}\left(3.664 \times 10^{-7} \mathrm{~A} \cdot \mathrm{cm}^{-2}\right)$ when the electrode initially entered a comparatively stable corrosion state. This coating also showed a higher critical potential of the oxidation film destruction $(0.313 \mathrm{~V})$ compared with Coating $1(0.050 \mathrm{~V})$ and Coating $3(0.290 \mathrm{~V})$.

Author Contributions: W.L.: Investigation, Experiment, Formal analysis, Writing—original draft. J.L.: Resources, Supervision, Methodology. Y.X.: Experiment, Formal analysis, Validation. All authors have read and agreed to the published version of the manuscript.

Funding: This research was funded by the National Natural Science Foundation of China, Grant No. 51471105, and Natural Science Foundation of Shanghai, Grant No. 20ZR1422200.

Institutional Review Board Statement: Not applicable.

Informed Consent Statement: Not applicable.

Data Availability Statement: Not applicable.

Acknowledgments: This work was financially supported by the National Natural Science Foundation of China (51471105) and Natural Science Foundation of Shanghai (20ZR1422200).

Conflicts of Interest: We declare that we do not have any commercial or associative interest that represents a conflict of interest in connection with the work submitted.

\section{References}

1. Fu, S.; Yang, L.; Wang, P.; Wang, S.; Li, Z. Comparison of the microstructure evolution and wear resistance of Ti6Al4V composite coatings reinforced by hard pure or Ni-plated cubic boron nitride particles prepared with laser cladding on a Ti6Al4V substrate. Coatings 2020, 10, 702. [CrossRef]

2. Xue, W.; Gao, S.; Duan, D.; Zhang, J.; Liu, Y.; Li, S. Effects of blade material characteristics on the high-speed rubbing be-havior between Al-hBN abradable seal coatings and blades. Wear 2018, 410, 25-33. [CrossRef]

3. Zhang, L.; Zhao, Z.; Bai, P.; Du, W.; Li, Y.; Yang, X.; Wang, Q. In-situ synthesis of TiC/graphene/Ti6Al4V composite coating by laser cladding. Mater. Lett. 2020, 270, 127711. [CrossRef]

4. Shi, C.; Lu, N.; Qin, Y.; Liu, M.; Li, H.; Li, H. Study on mechanical properties and permeability of elliptical porous scaffold based on the SLM manufactured medical Ti6Al4V. PLoS ONE 2021, 16, e0247764. [CrossRef]

5. Zhou, Z.Y.; Liu, X.B.; Zhuang, S.G.; Yang, X.H.; Wang, M.; Sun, C.F. Preparation and high temperature tribological proper-ties of laser in-situ synthesized self-lubricating composite coatings containing metal sulfides on Ti6Al4V alloy. Appl. Surf. Sci. 2019, 481, 209-218. [CrossRef]

6. Philip, J.T.; Mathew, J.; Kuriachen, B. Tribology of Ti6Al4V: A review. Friction 2019, 7, 497-536. [CrossRef]

7. Feng, Y.; Feng, K.; Yao, C.; Li, Z.; Sun, J. Microstructure and properties of in-situ synthesized $\left(\mathrm{Ti}_{3} \mathrm{Al}+\mathrm{TiB}\right) / \mathrm{Ti}$ composites by laser cladding. Mater. Des. 2018, 157, 258-272. [CrossRef]

8. Chen, S.; Li, L.; Chen, Y.; Huang, J. Joining mechanism of Ti/Al dissimilar alloys during laser welding-brazing process. J. Alloy. Compd. 2011, 509, 891-898. [CrossRef] 
9. Lu, X.L.; Liu, X.B.; Yu, P.C.; Qiao, S.J.; Zhai, Y.J.; Wang, M.D.; Chen, Y.; Xu, D. Synthesis and characterization of Ni60-hBN high temperature self-lubricating anti-wear composite coatings on Ti6Al4V alloy by laser cladding. Opt. Laser Technol. 2016, 78, 87-94. [CrossRef]

10. Liu, Y.; Li, J.; Xuan, F.Z. Fabrication of TiC reinforced Ni based coating by laser cladding. Surf. Eng. 2012, 28, 560-563. [CrossRef]

11. Miao, X.; Wu, M.; Cui, C.; Wang, H. Effect of graphene oxide on the performance of Co-based coatings on Ti6Al4V alloys by laser cladding. Coatings 2020, 10, 1048. [CrossRef]

12. Weng, F.; Yu, H.; Chen, C.; Liu, J.; Zhao, L.; Dai, J. Fabrication of Co-based coatings on titanium alloy by laser cladding with $\mathrm{CeO}_{2}$ addition. Mater. Manuf. Process. 2016, 31, 1461-1467. [CrossRef]

13. Chen, J.M.; Guo, C.; Zhou, J.S. Microstructure and tribological properties of laser cladding Fe-based coating on pure Ti substrate. Trans. Nonferrous Met. Soc. China 2012, 22, 2171-2178. [CrossRef]

14. Gao, W.; Zhang, Z.; Zhao, S.; Wang, Y.; Chen, H.; Lin, X. Effect of a small addition of Ti on the Fe-based coating by laser cladding. Surf. Coat. Technol. 2016, 291, 423-429. [CrossRef]

15. Wang, H.; Chen, T.; Cong, W.; Liu, D. Laser cladding of ti-based ceramic coatings on ti6al4v alloy: Effects of $\mathrm{CeO}_{2}$ nanoparticles additive on wear performance. Coatings 2019, 9, 109. [CrossRef]

16. Li, Y.; Su, K.; Bai, P.; Wu, L. Microstructure and property characterization of Ti/TiBCN reinforced Ti based composite coatings fabricated by laser cladding with different scanning speed. Mater. Charact. 2019, 159, 110023. [CrossRef]

17. Xiang, K.; Chai, L.; Wang, Y.; Wang, H.; Guo, N.; Ma, Y.; Murty, K.L. Microstructural characteristics and hardness of Co-NiTi medium-entropy alloy coating on pure Ti substrate prepared by pulsed laser cladding. J. Alloy. Compd. 2020, 849, 156704. [CrossRef]

18. Nazari, K.A.; Rashid, R.R.; Palanisamy, S.; Xia, K.; Dargusch, M. A novel Ti-Fe composite coating deposited using laser cladding of low cost recycled nano-crystalline titanium powder. Mater. Lett. 2018, 229, 301-304. [CrossRef]

19. Rashid, R.A.R.; Palanisamy, S.; Attar, H.; Bermingham, M.; Dargusch, M.S. Metallurgical features of direct la-ser-deposited Ti6Al4V with trace boron. J. Manuf. Process. 2018, 35, 651-656. [CrossRef]

20. Xuan, H.F.; Wang, Q.Y.; Bai, S.L.; Liu, Z.D.; Sun, H.G.; Yan, P.C. A study on microstructure and flame erosion mechanism of a graded Ni-Cr-B-Si coating prepared by laser cladding. Surf. Coat. Technol. 2014, 244, 203-209. [CrossRef]

21. Hemmati, I.; Ocelík, V.; de Hosson, J.T.M. Dilution effects in laser cladding of Ni-Cr-B-Si-C hardfacing alloys. Mater. Lett. 2012, 84, 69-72. [CrossRef]

22. Chen, J.; Li, J.; Song, R.; Bai, L.; Shao, J.; Qu, C. Effect of the scanning speed on microstructural evolution and wear behaviors of laser cladding NiCrBSi composite coatings. Opt. Laser Technol. 2015, 72, 86-99. [CrossRef]

23. Li, J.; Zhang, X.J.; Wang, H.P.; Li, M.P. Microstructure and mechanical properties of Ni-based composite coatings rein-forced by in situ synthesized $\mathrm{TiB}_{2}+\mathrm{TiC}$ by laser cladding. Int. J. Min. Met. Mater. 2013, 20, 57-64. [CrossRef]

24. Li, C.; Zhang, Q.; Wang, F.; Deng, P.; Lu, Q.; Zhang, Y.; Li, S.; Ma, P.; Li, W.; Wang, Y. Microstructure and wear behaviors of WC-Ni coatings fabricated by laser cladding under high frequency micro-vibration. Appl. Surf. Sci. 2019, 485, 513-519. [CrossRef]

25. Qu, C.; Li, J.; Bai, L.; Shao, J.; Song, R.; Chen, J. Effects of the thickness of the pre-placed layer on microstructural evolution and mechanical properties of the laser-clad coatings. J. Alloy. Compd. 2015, 644, 450-463. [CrossRef]

26. Wang, Y.; Liu, X.B.; Liu, Y.F.; Luo, Y.S.; Meng, Y. Microstructure and tribological performance of Ni60-based composite coatings on Ti6Al4V alloy with different $\mathrm{Ti}_{3} \mathrm{SiC}_{2}$ ceramic additions by laser cladding. Ceram. Int. 2020, 46, 28996-29010. [CrossRef]

27. Wu, F.; Chen, T.; Wang, H.; Liu, D. Effect of Mo on microstructures and wear properties of in situ synthesized Ti(C,N)/Ni-based composite coatings by laser cladding. Materials 2017, 10, 1047. [CrossRef]

28. Gao, Q.; Yan, H.; Qin, Y.; Zhang, P.; Guo, J.; Chen, Z.; Yu, Z. Laser cladding Ti-Ni/TiN/TiW+TiS/WS2 self-lubricating wear resistant composite coating on Ti6Al4V alloy. Opt. Laser. Technol. 2019, 113, 182-191. [CrossRef]

29. Sun, Y.; Hao, M. Statistical analysis and optimization of process parameters in Ti6Al4V laser cladding using Nd:YAG laser. Opt. Laser. Eng. 2012, 50, 985-995. [CrossRef]

30. Ochonogor, O.F.; Meacock, C.; Abdulwahab, M.; Pityana, S.; Popoola, A.P.I. Effects of Ti and TiC ceramic powder on laser-cladded Ti-6Al-4V in situ intermetallic composite. Appl. Surf. Sci. 2012, 263, 591-596. [CrossRef]

31. Lv, Y.H.; Li, J.; Tao, Y.F.; Hu, L.F. High-temperature wear and oxidation behaviors of TiNi/ $\mathrm{Ti}_{2} \mathrm{Ni}$ matrix composite coat-ings with TaC addition prepared on Ti6Al4V by laser cladding. Appl. Surf. Sci. 2017, 402, 478-494. [CrossRef]

32. Cai, J.; Yao, Y.; Gao, C.; Lyu, P.; Meng, X.; Guan, Q.; Li, Y.; Han, Z. Comparison of microstructure and oxidation behavior of NiCoCrAlYSi laser cladding coating before and after high-current pulsed electron beam modification. J. Alloy. Compd. 2021, 881, 160651. [CrossRef]

33. Okuno, T.; Kaneno, Y.; Yamaguchi, T.; Semboshi, S.; Hagino, H.; Takasugi, T. Microstructures and hardness properties of laser clad Ni base two-phase intermetallic alloy coating. J. Mater. Res. 2017, 32, 4531-4540. [CrossRef]

34. Li, N.; Xiong, Y.; Xiong, H.; Shi, G.; Blackburn, J.; Liu, W.; Qin, R. Microstructure, formation mechanism and property characterization of $\mathrm{Ti}+\mathrm{SiC}$ laser cladded coatings on Ti6Al4V alloy. Mater. Charact. 2019, 148, 43-51. [CrossRef]

35. Zhang, Z.; Yang, F.; Zhang, H.; Zhang, T.; Wang, H. Microstructure and element distribution of laser cladding TiC -reinforced $\mathrm{CrTi}_{4}$-based composite coating with $\mathrm{CeO}_{2} / \mathrm{Ce}_{2} \mathrm{O}_{3}$. Mater. Lett. 2021, 283, 128772. [CrossRef]

36. Bai, L.; Li, J.; Chen, J.; Song, R.; Shao, J.; Qu, C. Effect of the content of B4C on microstructural evolution and wear behaviors of the laser-clad coatings fabricated on Ti6Al4V. Opt. Laser Technol. 2016, 76, 33-45. [CrossRef] 
37. Obadele, B.; Andrews, A.; Olubambi, P.; Mathew, M.; Pityana, S. Effect of $\mathrm{ZrO}_{2}$ addition on the dry sliding wear behavior of laser clad Ti6Al4V alloy. Wear 2015, 328-329, 295-300. [CrossRef]

38. Li, J.; Yu, Z.; Wang, H. Wear behaviors of an (TiB + TiC)/Ti composite coating fabricated on Ti6Al4V by laser cladding. Thin Solid Films 2011, 519, 4804-4808. [CrossRef]

39. Yu, P.C.; Liu, X.B.; Lu, X.L.; Qiao, S.J.; Zhai, Y.J.; Zhu, G.X.; Wang, Y.G.; Chen, Y. Tribology and high-temperature oxidation behaviors of NiCrBSiFe composite coatings on Ti6Al4V alloy by laser cladding. RSC Adv. 2015, 5, 76516-76525. [CrossRef]

40. Kumar, S.; Mandal, A.; Das, A.K.; Dixit, A.R. Parametric study and characterization of AlN-Ni-Ti6Al4V composite clad-ding on titanium alloy. Surf. Coat. Technol. 2018, 349, 37-49. [CrossRef]

41. Adesina, O.S.; Farotade, G.A.; Popoola, P. Synthesis, parametric and tribological study of laser clad Co-Ni binary coatings on titanium alloy. Mater. Res. Express 2019, 6, 056512. [CrossRef]

42. Liu, H.; Zhang, X.; Jiang, Y.; Zhou, R. Microstructure and high temperature oxidation resistance of in-situ synthesized TiN/Ti 3 Al intermetallic composite coatings on Ti6Al4V alloy by laser cladding process. J. Alloy. Compd. 2016, 670, 268-274. [CrossRef]

43. Masanta, M.; Shariff, S.; Choudhury, A.R. Evaluation of modulus of elasticity, nano-hardness and fracture toughness of TiB ${ }_{2}-\mathrm{TiC}_{-}$ $\mathrm{Al}_{2} \mathrm{O}_{3}$ composite coating developed by SHS and laser cladding. Mater. Sci. Eng. A 2011, 528, 5327-5335. [CrossRef]

44. Zhao, P.; Li, J.; Zhang, Y.; Li, X.; Xia, M.; Yuan, B. Wear and high-temperature oxidation resistances of AlNbTaZrx high-entropy alloys coatings fabricated on Ti6Al4V by laser cladding. J. Alloy. Compd. 2021, 862, 158405. [CrossRef]

45. Rashid, R.A.R.; Abaspour, S.; Palanisamy, S.; Matthews, N.; Dargusch, M.S. Metallurgical and geometrical charac-terisation of the 316L stainless steel clad deposited on a mild steel substrate. Surf. Coat. Technol. 2017, 327, 174-184. [CrossRef]

46. Xu, C.; Gao, W. Pilling-Bedworth ratio for oxidation of alloys. Mater. Res. Innov. 2000, 3, 231-235. [CrossRef] 